\title{
REVSED The Multidimensional Battery of Prosody Perception
}

\section{(MBOPP) [version 2; peer review: 2 approved]}

\author{
Kyle Jasmin (D1), Frederic Dick (D)2, Adam Taylor Tierney²
}

${ }^{1}$ Department of Psychology, Royal Holloway, University of London, Ehgam, TW20 0EX, UK

${ }^{2}$ Psychological Sciences, Birkbeck University of London, London, WC1E 7HX, UK

\author{
V2 First published: 08 Jan 2020, 5:4 \\ https://doi.org/10.12688/wellcomeopenres.15607.1 \\ Latest published: 06 Oct 2021, 5:4 \\ https://doi.org/10.12688/wellcomeopenres.15607.2
}

\section{Open Peer Review}

Approval Status

1 2

version 2

(revision)

06 Oct 2021

version 1

08 Jan 2020

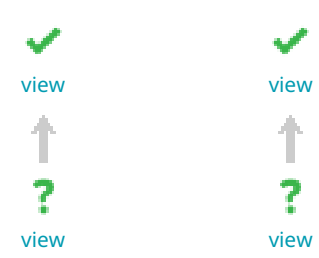

1. Margriet A. Groen ID, Lancaster University, Lancaster, UK

2. Robert Fuchs (D), University of Hamburg, Hamburg, Germany

Any reports and responses or comments on the article can be found at the end of the article.

prosody, auditory, language, pitch, duration 
Corresponding author: Kyle Jasmin (Kyle.Jasmin@rhul.ac.uk)

Author roles: Jasmin K: Conceptualization, Methodology, Writing - Original Draft Preparation, Writing - Review \& Editing; Dick F: Conceptualization, Methodology, Supervision; Tierney AT: Conceptualization, Formal Analysis, Funding Acquisition, Investigation, Methodology, Supervision, Validation, Visualization, Writing - Original Draft Preparation, Writing - Review \& Editing

Competing interests: No competing interests were disclosed.

Grant information: The work was funded by a Wellcome Trust Seed Award (109719) to A.T.T., a Reg and Molly Buck Award from SEMPRE to K.J., and a Leverhulme Trust Early Career Fellowship to K.J. (ECF-2017-151).

The funders had no role in study design, data collection and analysis, decision to publish, or preparation of the manuscript.

Copyright: (c) 2021 Jasmin $\mathrm{K}$ et al. This is an open access article distributed under the terms of the Creative Commons Attribution License, which permits unrestricted use, distribution, and reproduction in any medium, provided the original work is properly cited.

How to cite this article: Jasmin K, Dick F and Tierney AT. The Multidimensional Battery of Prosody Perception (MBOPP) [version 2; peer review: 2 approved] Wellcome Open Research 2021, 5:4 https://doi.org/10.12688/wellcomeopenres.15607.2

First published: 08 Jan 2020, 5:4 https://doi.org/10.12688/wellcomeopenres.15607.1 


\section{REVISED Amendments from Version 1}

This version addresses reviewers' comments, and also presents a dataset that is different from the first version (new participants, run entirely online, each participant judged each item in each condition) which is now registered on Open Science Framework The new results largely replicate the results in the first version. The stimuli are exactly the same as in the first version, and none of the methodological details concerning the stimuli have changed.

Any further responses from the reviewers can be found at the end of the article

\section{Introduction}

\section{Multiple dimensions for prosody}

One of the main tasks in speech perception is categorizing a continuous stream of speech sounds into linguistically informative phonemes or syllables (Holt \& Lotto, 2010). However, speech contains acoustic patterns on longer time scales as well. These suprasegmental or prosodic patterns convey crucial disambiguating lexical, syntactic, and emotional cues that help the listener capture the intended message of the talker. In English, prosodic features can be conveyed by many acoustic dimensions, including changes in pitch, amplitude, and the duration of elements. For example, prosodic focus, which helps listeners direct attention to particularly important words or phrases in a sentence, is typically cued by an increase in the amplitude and duration of the emphasized elements, along with exaggerated pitch excursion (Breen et al., 2010; Fry, 1958; see Figure 1a, b for an example). Listeners can use focus to determine the portion of the sentence to which they should be directing their attention. Similarly, lexical stress is cued by a combination of increased amplitude, pitch changes, and increased syllable duration (Chrabaszcz et al., 2014; Mattys, 2000). Listeners can use stress to help distinguish between different words (i.e. "PREsent" versus "preSENT") and to detect word boundaries (Nakatani \& Schaffer, 1978). Finally, phrase boundaries tend to coincide with a change in pitch and lengthening of the syllable just prior to the boundary (Choi et al., 2005; Cumming, 2010; de Pijper \& Sanderman, 1994; Streeter, 1978).

Listeners can make use of such prosodic cues to clarify potentially ambiguous syntactic structures in a sentence (Beach, 1991; Frazier et al., 2006; Jasmin et al., 2020; Lehiste et al., 1976; Marslen-Wilson et al., 1992). In fact, prosodic patterns may be a more powerful cue to phrase structure than statistical patterns, as artificial grammar learning experiments have shown that when prosodic cues and transitional probabilities are pitted against one another, listeners will learn hierarchical

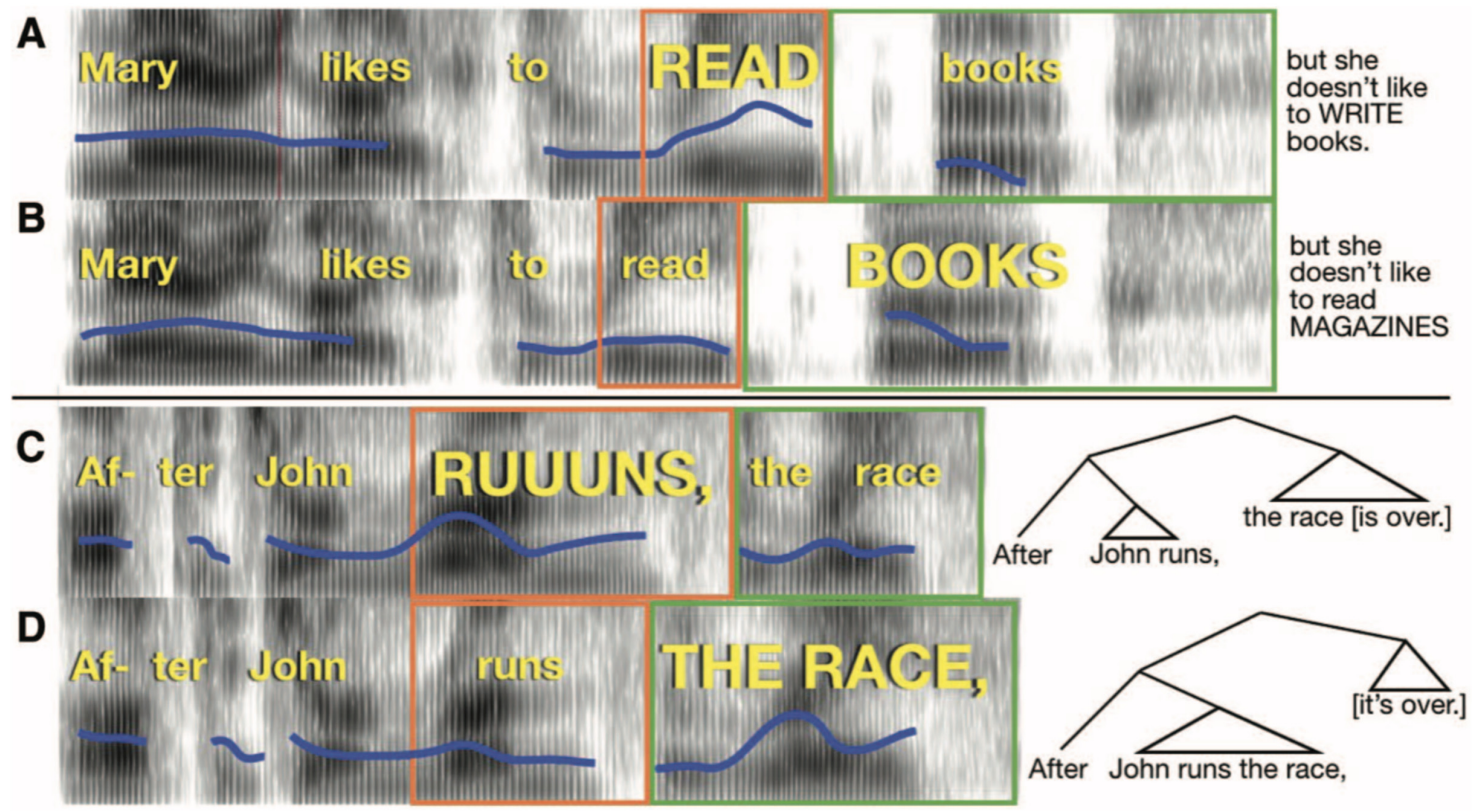

Figure 1. Pitch and duration (time) correlates of emphatic accents and phrase boundaries. Example spectrograms of stimuli used in the experiment (time on horizontal axis, frequency on vertical axis, and amplitude in grayscale), with linguistic features cued simultaneously by pitch and duration (the "Combined" condition). The blue line indicates the fundamental frequency of the voice. The width of the orange and green boxes indicates the duration of the words within the box. (A) An emphatic accent places focus on "read". Completion of the sentence appears to the right. (B) An emphatic accent places focus on "books"; sentence completion is at right. (C) A phrase boundary occurs after "runs". (D) A phrase boundary occurs after "race". Syntactic trees are indicated at right to illustrate the structure conveyed by the acoustics of the stimuli. 
structure which reflects prosodic information (Langus et al., 2012).

\section{Prosody and reading acquisition}

Given the useful information prosodic cues provide about the structure of language, accurate prosody perception may be a crucial foundational skill for successful acquisition of language. Indeed, phonemic and prosodic awareness are independent predictors of word reading (Clin et al., 2009; Defior et al., 2012; Goswami et al., 2013; Holliman et al., 2010a; Jiménez-Fernández et al., 2015; Wade-Woolley, 2016; for a review see Wade-Woolley \& Heggie, 2015), suggesting that prosody perception forms a separate dimension of linguistic skill relevant to reading acquisition. The link between prosody and reading is not limited to word reading, as prosody perception and production have also been shown to be related to reading comprehension (Holliman et al., 2014). Prosody predicts reading comprehension even when a variety of additional linguistic variables are accounted for, including phonological skills and vocabulary (Breen et al., 2016; Holliman et al., 2010b; Lochrin et al., 2015; Whalley \& Hansen, 2006), syntactic awareness (Veenendaal et al., 2014), and decoding (Groen et al., 2019). This link between prosodic skills and reading comprehension could reflect links between prosodic and syntactic processing during reading. Fodor (1998), for example, proposed that readers generate prosodic contours during silent reading, and that these prosodic structures can affect syntactic parsing decisions, a hypothesis later supported by eye-tracking data (Kentner, 2012).

Not only has dyslexia been linked to impaired prosody perception (Goswami et al., 2010; Holliman et al., 2010a; Mundy \& Carroll, 2012; Wade-Woolley, 2016; Wood \& Terrell, 1998), but in adolescents with dyslexia, difficulties with the perception of lexical stress have been shown to be more prominent than problems with segmental phonology (Anastasiou \& Protopapas, 2015). Finally, prosodic sensitivity also predicts word reading one year later (Calet et al., 2015; Holliman et al., 2010b), suggesting that prosody perception is a foundational skill upon which children draw when learning to read.

Such links between prosodic awareness and language acquisition suggest that the difficulties with prosody perception that accompany certain clinical diagnoses may have consequences for language acquisition. For example, some individuals with autism spectrum disorders (ASD) produce speech which lacks the usual acoustic characteristics which mark particular prosodic features; for example, the difference in duration between stressed and unstressed syllables tends to be smaller in the speech of children with ASD (Paul et al., 2008). These prosodic production deficits extend to perception as well: individuals with ASD tend to have difficulty with the perception of prosodic cues to emotion (Globerson et al., 2015; Golan et al., 2007; Kleinman et al., 2001; Philip et al., 2010; Rutherford et al., 2002), lexical stress (Kargas et al., 2016), phrase boundaries (Diehl et al., 2008), and linguistic focus (Peppé et al., 2011) in speech (but see Diehl et al., 2015). These prosody perception difficulties can interfere not only with communication skill and sociability (Paul et al., 2005), but may also increase the risk of delayed language acquisition given the importance of prosody for disambiguating language meaning (Lyons et al., 2014).

\section{Prosody and language disorders}

Prosody perception is, therefore, a vital skill supporting language development, and is impaired in several clinical populations in which there is intense interest. As mentioned above, prosodic features tend to be conveyed by a mixture of multiple different cues, including changes in the pitch and duration of syllables and words. As a result, one source of difficulties with prosody perception may be impairments in auditory processing, a possibility supported by findings that prosody perception in children correlates with psychophysical thresholds for pitch, duration, and amplitude rise time (Goswami et al., 2013; Haake et al., 2013; Richards \& Goswami, 2015). However, impairments in auditory processing can be present for one dimension in the presence of preserved processing in other dimensions. In particular, impaired pitch perception can co-occur with preserved duration perception (and vice versa - Kidd et al., 2007). Similarly, research on amusia has shown that highly impaired memory for pitch sequences can co-occur with preserved memory for durational sequences (Hyde \& Peretz, 2004). A prosody perception deficit in a given individual, therefore, could reflect impaired pitch perception or duration perception or both. Existing methodologies for assessing prosody perception, however, cannot control the acoustic cues to different prosodic features, and therefore cannot diagnose the source of an individual's prosodic impairment.

\section{Existing prosody tests}

Although there exist many widely available standardized tests of segmental speech perception usable by individuals of all ages (Killion et al., 2004; Nilsson et al., 1994; Wilson, 2003), there are comparatively few instruments publicly available for researchers and clinicians interested in testing suprasegmental speech perception. Consequently, prosody perception research has been carried out using a wide variety of in-house methods developed within single laboratories, making comparison across studies difficult. These include perceptual matching tasks such as matching low-pass filtered sentences or indicating whether the prosodic structure of low-pass filtered sentences match unfiltered target sentences (Cumming et al., 2015; Fisher et al., 2007; Wood \& Terrell, 1998). Participants have also been asked to match the stress pattern of a nonsense phrase like "DEEdee DEEdee" with a spoken target phrase like "Harry Potter" (Goswami et al., 2010; Holliman et al., 2012; Mundy \& Carroll, 2012; Whalley \& Hansen, 2006). These tests have the advantage of isolating the suprasegmental elements of speech. However, because these tests do not use actual language, they arguably measure auditory discrimination rather than prosody perception per se. Moreover, these tests are not publicly available.

A widely used battery of prosody perception available for purchase by the public is the Profiling Elements of Prosodic Systems-Children test, or PEPS-C (Peppé \& McCann, 2003). This test assesses the perception and production of four 
different aspects of prosody: affect, phrase structure, focus, and interaction. Each subtest features two different sets of trials. In "form" trials, the listener is asked to make same/different judgments on utterances which either do or do not differ based on a prosodic feature. In "function" trials, the listener is asked to infer the speaker's intent by detecting a prosodic feature. For example, one item from the phrase structure subtest asks listeners to point to the picture that best fits the utterance "fish, fingers, and fruit" (as opposed to "fish fingers and fruit"; NB:British English "fish fingers" are called "fish sticks" in American English). This test has been successfully used to study a variety of topics related to prosody perception in children, including the relationship between prosody perception and reading ability in typically developing children (Lochrin et al., 2015), and impairments in prosody perception in children with specific language impairment, dyslexia, and ASD (Jarvinen-Pasley et al., 2008a; Marshall et al., 2009; Wells \& Peppé, 2003).

The main limitation of the PEPS-C is that it was designed to be administered to children, and therefore many adults would perform at ceiling. The PEPS-C was adapted from an earlier battery designed to be used with adults (the PEPS), but it is not available for use by the public, and there is also evidence for the existence of ceiling effects in adult PEPS data (Peppé et al., 2000). Moreover, there are a number of examples of ceiling effects in the literature on prosody perception in adolescents and adults in research using other prosody perception tests (Chevallier et al., 2009; Lyons et al., 2014; Paul et al., 2005), suggesting that existing methodologies for testing prosody perception are insufficiently challenging for adult participants. Research on prosody would be facilitated by a publicly available test with adaptive difficulty suitable for a range of ages and backgrounds.

\section{The current study}

Here we report and make publicly available the Multidimensional Battery of Prosody Perception (MBOPP), a battery of prosody perception with adaptive difficulty which is therefore suitable for participants of all ages, backgrounds, and ability levels. This battery consists of two tests, one assessing the perception of linguistic focus and another assessing the perception of phrase boundaries. For both tests, stimuli were constructed by asking an actor to read aloud sequences of words which were identical lexically but differed on the presence of a prosodic feature. Thus, each sentence in the focus test has an "early focus" and "late focus" version, referring to the relative position of emphasized elements. Similarly, the sentences in the phrase test have an "early closure" and "late closure" version, referring to the placement of the phrase boundary (indicated typographically with a comma). Speech morphing software (STRAIGHT, Kawahara \& Irino, 2005) was then used to decompose these two recordings, align them onto one another, and resynthesize ("morph") them such that the extent to which pitch and durational patterns cued one prosodic interpretation or the other could be varied independently while all other acoustic characteristics are set to be intermediate between the two recordings. This method allows the researcher to tune the difficulty of the test to any population (by choosing which subset of stimuli to use) and enables investigation of dimension-specific prosody perception. This test was presented to 57 typically developed adult participants to examine the relative usefulness of pitch versus durational cues for focus and phrase boundary perception, and to measure the reliability of each subtest.

\section{Methods}

\section{Participants}

Participants ( $\mathrm{N}=59,34 \mathrm{~F}, 24 \mathrm{M}, 1$ non-binary by self-ID, aged 29.0 \pm 6.1 ) were recruited using Prolific - an online participant recruitment portal - in exchange for payment after the session. All participants were native English speakers of British English. The same participants completed both the focus perception and phrase perception tasks.

\section{Materials - Focus Perception}

The Focus Perception test consists of 47 compound sentences (two independent clauses separated by a conjunction; Table 1). We recorded spoken versions of these sentences in a quiet room using a Rode NT1-A condenser microphone $(44.1 \mathrm{kHz}$, 32-bit) as they were spoken by a former professional actor, now a speech researcher. The actor placed contrastive accents to emphasize the capitalized words in the sentences. Each of the sentences was read with emphasis on two different word pairs, thus creating two versions: an "early focus" version (e.g., "Mary likes to READ books, but she doesn't like to WRITE them," focus indicated by upper-case letters), and "late focus", where the focus elements occurred in later positions in the sentence (e.g., "Mary likes to read BOOKS, but she doesn't like to read MAGAZINES," focus indicated by upper-case letters; Figure 1a, b). Thus, the emphasis placed on the words in capitalized letters served to indicate contrastive focus, meant to indicate which linguistic elements (words, in this case) should receive greater attention to clarify the speaker's intentions. For example, suppose the conversation began as follows:
A. Why doesn't Mary like books?
B. She likes to READ books, but not WRITE them.

The focused elements spoken by B serve to contrast with the presupposition by speaker A. The terms "early focus" and "late focus" used in this article refer simply to which pair of words is emphasized (e.g. READ and WRITE occur earlier than BOOKS and MAGAZINES, respectively.)

The audio recordings of these sentences were trimmed such that they included only the first clause, which consisted of identical words in each version (this clause is indicated in the examples above via underlining). The raw recordings of "early" and "late" focus sentences were then morphed together to create intermediate versions. Morphing was performed with STRAIGHT software (Kawahara \& Irino, 2005). The two recordings of each sentence (differing only in the placement of the emphasized word) were manually time-aligned by examining a similarity matrix created from the two recordings and manually marking anchor points at energy changes (e.g. bursts) in 
Table 1. Text of Focus Stimuli Sentences.

\begin{tabular}{|c|c|c|c|c|c|c|}
\hline$\#$ & Start & $\begin{array}{l}\text { Focused } \\
\text { Word } 1\end{array}$ & $\begin{array}{l}\text { Focused } \\
\text { Word } 2\end{array}$ & Middle & Ending 1 & Ending 2 \\
\hline 1 & Mary likes to & read & books & but she doesn't like to & WRITE books & read MAGAZINES \\
\hline 2 & Alice sometimes & pets & dogs & but she won't & WASH dogs & pet CATS \\
\hline 5 & Dave likes to & study & music & but he doesn't like to & PLAY music & study HISTORY \\
\hline 6 & Sally has a & Windows & computer & but she really wants & an APPLE computer & a Windows TABLET \\
\hline 7 & George asked for a & white & Americano & but the barista gave him a & BLACK Americano & white filter COFFEE \\
\hline 8 & Fiona was eating & strawberry & yoghurt & but she really wanted some & BLUEBERRY yoghurt & strawberry ICECREAM \\
\hline 9 & Tom likes & barbecue & chicken & but not as much as & ROAST chicken & barbecue PORK \\
\hline 10 & Sophie likes to & paint & landscapes & but she doesn't like to & DRAW landscapes & paint PORTRAITS \\
\hline 11 & John can't & run & a marathon & but he could & WALK a marathon & run a MILE \\
\hline 12 & Matt is good at & flying & planes & but he isn't good at & LANDING planes & flying HELICOPTERS \\
\hline 13 & Pippa found a & jam & jar & but she couldn't find a & JELLY jar & jam KNIFE \\
\hline 14 & Sam has a & fish & knife & but he doesn't have a & BUTTER knife & fish FORK \\
\hline 15 & Rachel likes & French & food & but she doesn't like & ITALIAN food & French WINE \\
\hline 16 & The woman likes & white & pearls & but not & BLACK pearls & white DIAMONDS \\
\hline 17 & Ken won't buy & Sainsbury's & pizza & but he will buy & TESCO'S pizza & Sainsbury's CHICKEN \\
\hline 18 & Sarah has a & Barclay's & card & but she doesn't have a & LLOYDS card & Barclay's MORTGAGE \\
\hline 19 & Neil won't support & Oxford's & $\begin{array}{l}\text { fencing } \\
\text { team }\end{array}$ & but he will support & $\begin{array}{l}\text { CAMBRIDGE'S } \\
\text { fencing team }\end{array}$ & Oxford's ROWING team \\
\hline 20 & Carolyn likes & Scottish & pubs & but she doesn't like & ENGLISH pubs & Scottish RESTAURANTS \\
\hline 21 & Micah has been to & Regent's & park & but he hasn't been to & HYDE Park & Regent's STREET \\
\hline 22 & Rosalyn likes to & drink & beer & but she doesn't like to & BREW beer & drink LIQUOR \\
\hline 23 & Veronica has visited & America & for holiday & but she hasn't visited & CANADA for holiday & America FOR WORK \\
\hline 24 & Tim has an & electric & piano & but he really wants an & ACOUSTIC piano & electric GUITAR \\
\hline 25 & Ben has ridden a & UK & train & but he has never ridden a & AMERICAN train & UK BUS \\
\hline 26 & Nancy has a & small & flat & but she would really like a & LARGE flat & small HOUSE \\
\hline 27 & Paul's house has a & brown & sofa & but it doesn't have a & BLACK sofa & brown CHAIR \\
\hline 28 & Robert doesn't like & Dutch & cinema & but he does like & GERMAN cinema & Dutch THEATRE \\
\hline 29 & Jenny doesn't have any & ginger & friends & but she does have several & BLONDE friends & ginger COLLEAGUES \\
\hline 30 & You shouldn't open the & red & suitcase & but you can open the & GREEN suitcase & red CHEST \\
\hline 31 & Emma doesn't & speak & well & but she does & DRESS well & speak OFTEN \\
\hline 32 & Rose has visited & southern & Greece & but she has not visited & NORTHERN Greece & southern ITALY \\
\hline 33 & Jane can speak & modern & Greek & but she can't speak & ANCIENT Greek & modern EGYPTIAN \\
\hline 34 & jim likes & Boots' & shampoo & but he doesn't like & $\begin{array}{l}\text { SUPERDRUG } \\
\text { shampoo }\end{array}$ & Boots' BODYWASH \\
\hline 35 & $\begin{array}{l}\text { Cameron will } \\
\text { sometimes }\end{array}$ & watch & basketball & but he will never & PLAY basketball & watch CRICKET \\
\hline 36 & Terry buys & sparkling & water & but not & STILL water & sparkling WINE \\
\hline
\end{tabular}




\begin{tabular}{|c|c|c|c|c|c|c|}
\hline \# & Start & $\begin{array}{l}\text { Focused } \\
\text { Word } 1\end{array}$ & $\begin{array}{l}\text { Focused } \\
\text { Word } 2\end{array}$ & Middle & Ending 1 & Ending 2 \\
\hline 37 & Richard said to buy & red & cups & but not & BLUE cups & red PLATES \\
\hline 38 & Harriet can & speak & Mandarin & but she can't & READ Mandarin & speak CANTONESE \\
\hline 39 & Olivia was looking for & wooden & boats & but she only found & PLASTIC boats & wooden PLANES \\
\hline 40 & Michael likes to & plant & flowers & but he hates to & PICK flowers & plant POTATOES \\
\hline 41 & Cathy likes to & observe & children & but she doesn't like to & TALK to children & observe ADULTS \\
\hline 42 & Lily likes to & buy & stocks & but she doesn't like to & SELL stocks & buy BONDS \\
\hline 43 & Alex likes to & collect & dolls & but he doesn't like to & PLAY with dolls & collect STAMPS \\
\hline 44 & Frank has a & toy & dog & but he would really like a & REAL dog & toy BIRD \\
\hline 46 & Bonnie has an & American & visa & but she really wants a & BRITISH visa & American PASSPORT \\
\hline 47 & Patsy likes & Starbucks & coffee & but her friends like & COSTA coffee & Starbucks TEA \\
\hline 48 & Timothy bought a & leather & jacket & because he couldn't find & a CLOTH jacket & leather SHOES \\
\hline 49 & Carrie likes & Star Trek & films & but she can't stand & Star WARS films & Star TREK cartoons \\
\hline 50 & Daniel enjoys & Chicago & pizza & but he doesn't care for & NEW YORK pizza & Chicago BEER \\
\hline
\end{tabular}

each recording. After establishing these anchor points, morphed intermediate versions of the sentences were synthesized. An experimenter listened to the result of the morphing to check the quality of the output. If quality was low, anchor points were added or adjusted and the procedure was repeated until the resulting morph sounded natural. STRAIGHT allows morphs along several dimensions: Aperiodicity, Spectrum, Frequency, Time (duration), and F0 (pitch). For the morphs created for this prosody battery, only Duration and Pitch were manipulated.

We are distributing this stimulus set (see Extended data; Jasmin, 2021) with morphs in three conditions: Pitch, Time, and Combined. The Combined condition consists of stimuli in which duration and pitch information cue emphasis on the same word -- either early focus or late focus (e.g. Mary likes to READ books vs Mary likes to read BOOKS). Morphing rates are expressed in terms of percent, such that lower values indicate more information from the early focus recording, and higher values indicate more information from the late focus recording, while $50 \%$ indicates an equal amount of a given dimension from each recording.

For stimuli in the Pitch condition, the emphasized word in the sentence is conveyed by pitch cues alone which vary from $0 \%$ (pitch information coming entirely from the early focus recording) to $100 \%$ (pitch information coming from the late focus recording), while duration cues are ambiguous with the Time parameter always set at $50 \%$. In the Duration condition, emphasis is conveyed only by durational cues, which similarly vary from $0 \%$ to $100 \%$, while pitch cues are ambiguous, always set at 50\%. The other morphing dimensions available in STRAIGHT (Aperiodicity, Spectrum, and
Frequency) were held at $50 \%$ such that morphs contained equal amounts of information from the two recordings.

Table 2 displays the morphing rates included in the stimuli published with this article. The file naming format for the stimuli is as follows.

[Stimulus number] _ [pitch morphing rate] _ [duration morphing rate] .wav

Examples:

- Focus1_pitch0_time0.wav - pitch and duration both cue EARLY focus (Combined)

- Focus1_Pitch100_time100.wav - pitch and duration both cue LATE focus (Combined)

- Focus1_pitch50_time0.wav - pitch is ambiguous, only duration cues EARLY focus (Time)

- Focus1_pitch50_time100.wav - pitch is ambiguous, only duration cues LATE focus (Time)

- Focus1_pitch0_time50.wav - duration is ambiguous, only pitch cues EARLY focus (Pitch)

- Focus1_pitch100_time50.wav - duration is ambiguous, only pitch cues LATE focus (Pitch)

For the experiments included in this report, these six different kinds of morphs were created by varying the amount of pitch-related and time information either independently or simultaneously. For the Pitch condition, duration morphing rates were held at $50 \%$, while two contrasting pitch versions 
Table 2. Morphing rates for Phrase and Focus test stimuli.

\begin{tabular}{|l|l|l|}
\hline Condition & Pitch Morphing Rate & Duration Morphing Rate \\
\hline Pitch & 0\% to $40 \%, 60$ to $100 \%$, in 5\% increments & Always $50 \%$ \\
\hline Duration & Always $50 \%$ & $0 \%$ to $40 \%, 60$ to $100 \%$, in $5 \%$ increments \\
\hline Combined & $0 \%$ to $40 \%, 60$ to $100 \%$, in $5 \%$ increments & $0 \%$ to $40 \%, 60$ to $100 \%$, in $5 \%$ increments \\
\hline
\end{tabular}

were created at 25\% (towards early focus) and $75 \%$ (towards late focus). For the Duration condition, pitch was held at $50 \%$ while duration was manipulated to be $25 \%$ (early focus) or $75 \%$ (late focus). For the Combined condition, both the pitch and the Duration dimensions were manipulated simultaneously to be $25 \%$ or $75 \%$. Morphing rates of $25 \%$ (instead of $0 \%$ ) and $75 \%$ (instead of $100 \%$ ) were used to make the task more difficult. The task could be made yet more difficult by moving these values even closer to $50 \%$ (e.g. $40 \%$ for early focus and $60 \%$ for late focus). All files were saved and subsequently presented at a sampling rate $44.1 \mathrm{kHz}$ with 16-bit quantization.

The text of the stimuli are given in Table 1. The auditory recordings consist of the following portions of the text: Start, Focused Word 1, Focused Word 2.

\section{Procedure - Focus Perception}

Performance and reliability data reported here were collected with Gorilla Experiment Builder (Anwyl-Irvine et al., 2019). We tested participants' ability to detect prosodic differences by asking them to match auditory versions of sentences with text ones. Participants read sentences presented visually on the screen one at a time, which were either early or late focus. For example, one visually presented sentence was "Mary likes to READ books, but she doesn't like to WRITE books."

The emphasized words appeared in all upper-case letters, as in the example above. Subjects were then given 4 seconds to read the sentence to themselves silently and imagine how it should sound if someone spoke it aloud. Following this, subjects heard the early focus and late focus versions of the first independent clause of the stimulus sentence (up to but not including the conjunction). The order of the presentation was randomized. Participants decided which of the two readings contained emphasis placed on the same word as in the text sentence and responded by pressing " 1 " or " 2 " on the keyboard to indicate if they thought the first version or second version was spoken in a way that better matched the on-screen version of the sentence. The stimuli were divided into three lists (47 trials each) and counterbalanced such that participants heard an equal number of Pitch, Duration and Combined stimulus examples. For 23 of the stimuli, presentations featured the early focus version; for the remaining stimuli, the presentation was late focus. Each participant judged each stimulus in each of the conditions, spread across the 3 lists. The entire task lasted approximately 30 minutes.

\section{Materials - Phrase Perception}

The Phrase Perception test stimuli consisted of 42 pairs of short sentences with a subordinate clause appearing before a main clause (see Figure 1c, d). About half of these came from a published study (Kjelgaard \& Speer, 1999) and the rest were created for this test (see Table 3). The sentence pairs consisted of two similar sentences, the first several words of which were identical. In the first type of sentence, "early closure", the subordinate clause's verb was used intransitively, and the following noun was the subject of a new clause ("After John runs, the race is over"). In the second type of sentence, "late closure", the verb was used transitively and took the immediately following noun as its object, which caused a phrase boundary to occur slightly later in the sentence than in the early close version ("After John runs the race, it's over"). Both versions of the sentence were lexically identical from the start of the sentence until the end of the second noun. The same actor recorded early and late closure versions of the sentences in his own standard Southern English dialect. The recordings were cropped such that only the lexically identical portions of the two versions remained, and silent pauses after phrase breaks were removed.

Auditory stimuli for the phrase test were created in the same way as in the focus test, by asking an actor to read aloud the two versions of each sentence (the early and late closure). Then the recordings were cropped to the lexically identical portions, corresponding anchor points were defined, and morphs were created in STRAIGHT. The morphs we publish here were created with the same proportions as in the focus test (Table 2).

Phrase Perception test procedure. For the validation experiments reported here, we used stimuli with early or late closure cued by $75 \%$ and $25 \%$ morphing rates. The procedure for the Linguistic Phrase test was similar to that of the Linguistic Focus Test. On each trial, participants read a text version of each sentence online, which was either early or late closure, as indicated by the grammar of the sentence and a comma placed after the first clause (Figure 1c, d). Participants read the sentence to themselves silently and imagined how it should sound if someone spoke it aloud. Following this, subjects heard the first part of the sentence (which was lexically identical in the early and late closure versions) spoken aloud, in two different ways, one that cued an early closure reading and another that cued a late closure reading. Participants decided which of the two readings best reflected the text sentence 
Table 3. Text of the Phrase Test sentences, each of which has two versions, where a phrase boundary occurs either earlier or later in the sentence.

\begin{tabular}{|c|c|c|c|}
\hline$\#$ & Closure & Start & Finish \\
\hline 1 & Early & After Jane dusts, the dining table & is clean \\
\hline 1 & Late & After Jane dusts the dining table, & it's clean \\
\hline 2 & Early & After John runs, the race & is over \\
\hline 2 & Late & After John runs the race, & it's over \\
\hline 5 & Early & Because Mike phoned, his mother & was relieved \\
\hline 5 & Late & Because Mike phoned his mother, & she was relieved \\
\hline 7 & Early & Because Sarah answered, the teacher & was proud \\
\hline 7 & Late & Because Sarah answered the teacher, & she was proud \\
\hline 8 & Early & Because Tara cleaned, the house & was spotless \\
\hline 8 & Late & Because Tara cleaned the house, & it was spotless \\
\hline 9 & Early & Because George forgot, the party & had started \\
\hline 9 & Late & Because George forgot the party, & he was sad \\
\hline 10 & Early & Because Mike paid, the bill & was smaller \\
\hline 10 & Late & Because Mike paid the bill, & it was smaller \\
\hline 13 & Early & If Charles is baby-sitting, the children & are happy \\
\hline 13 & Late & If Charles is baby-sitting the children, & they're happy \\
\hline 14 & Early & If George is programming, the computer & is busy \\
\hline 14 & Late & If George is programming the computer, & it's busy \\
\hline 15 & Early & If Ian doesn't notice, Beth & is fine \\
\hline 15 & Late & If Ian doesn't notice Beth, & it's fine \\
\hline 16 & Early & If Joe starts, the meeting & will be long \\
\hline 16 & Late & If Joe starts the meeting, & it'll be long \\
\hline 18 & Early & If Laura is folding, the towels & will be neat \\
\hline 18 & Late & If Laura is folding the towels, & they'll be neat \\
\hline 19 & Early & When the baby finishes, the bottle & will be empty \\
\hline 19 & Late & When the baby finishes the bottle, & it'll be empty \\
\hline 20 & Early & If Barbara gives up, the ship & will be plundereo \\
\hline 20 & Late & If Barbara gives up the ship, & it'll be plundered \\
\hline 21 & Early & If the Scissor Sisters open, the show & will be great \\
\hline 21 & Late & If the Scissor Sisters open the show, & it'll be great \\
\hline 22 & Early & If the maid packs, the suitcase & will be tidy \\
\hline 22 & Late & If the maid packs the suitcase, & it'll be tidy \\
\hline 23 & Early & If Tom wins, the contest & is over \\
\hline 23 & Late & If Tom wins the contest, & it's over \\
\hline 24 & Early & If the doctor calls, your sister & will answer \\
\hline 24 & Late & If the doctor calls your sister, & she'll answer \\
\hline
\end{tabular}




\begin{tabular}{|c|c|c|c|}
\hline$\#$ & Closure & Start & Finish \\
\hline 25 & Early & If Jack cleans, the kitchen & will be filthy \\
\hline 25 & Late & If Jack cleans the kitchen, & it'll be filthy \\
\hline 26 & Early & If dad digs, the hole & will be deep \\
\hline 26 & Late & If dad digs the hole, & it'll be deep \\
\hline 27 & Early & When a man cheats, his friends & get angry \\
\hline 27 & Late & When a man cheats his friends, & they're angry \\
\hline 29 & Early & When Gaga sings, the song & is a hit \\
\hline 29 & Late & When Gaga sings the song, & it's a hit \\
\hline 30 & Early & When Roger leaves, the house & is dark \\
\hline 30 & Late & When Roger leaves the house, & it's dark \\
\hline 31 & Early & When Suzie visits, her grandpa & is happy \\
\hline 31 & Late & When Suzie visits her grandpa, & he's happy \\
\hline 32 & Early & When the clock strikes, the hour & has started \\
\hline 32 & Late & When the clock strikes the hour, & it's started \\
\hline 33 & Early & When the guerrillas fight, the battle & has begun \\
\hline 33 & Late & When the guerrillas fight the battle, & it's begun \\
\hline 34 & Early & When the maid cleans, the rooms & are organized \\
\hline 34 & Late & When the maid cleans the rooms, & they're organized \\
\hline 35 & Early & When the original cast performs, the play & is fantastic \\
\hline 35 & Late & When the original cast performs the play, & it's fantastic \\
\hline 36 & Early & When Tim is presenting, the lectures & are interesting \\
\hline 36 & Late & When Tim is presenting the lectures, & $\begin{array}{l}\text { they're } \\
\text { interesting }\end{array}$ \\
\hline 37 & Early & When The Beatles play, the music & is noisy \\
\hline 37 & Late & When The Beatles play the music, & it's noisy \\
\hline 38 & Early & When Paul drinks, the rum & disappears \\
\hline 38 & Late & When Paul drinks the rum, & it disappears \\
\hline 39 & Early & When Mary helps, the homeless & are grateful \\
\hline 39 & Late & When Mary helps the homeless, & they're grateful \\
\hline 40 & Early & When the phone loads, the app & crashes \\
\hline 40 & Late & When the phone loads the app, & it crashes \\
\hline 41 & Early & When the shop closes, its doors & are locked \\
\hline 41 & Late & When the shop closes its doors, & they're locked \\
\hline 42 & Early & When a train passes, the station & shakes \\
\hline 42 & Late & When a train passes the station, & it shakes \\
\hline 43 & Early & When the actor practices, the monologue & is excellent \\
\hline 43 & Late & When the actor practices the monologue, & it's excellent \\
\hline 44 & Early & When the cowboy rides, the horse & is tired \\
\hline
\end{tabular}




\begin{tabular}{|l|l|l|l|}
\hline \# & Closure & Start & Finish \\
\hline $\mathbf{4 4}$ & Late & When the cowboy rides the horse, & it's tired \\
\hline $\mathbf{4 6}$ & Early & Whenever the guard checks, the door & is locked \\
\hline $\mathbf{4 6}$ & Late & Whenever the guard checks the door, & it's locked \\
\hline $\mathbf{4 7}$ & Early & Whenever Bill teaches, the course & is boring \\
\hline $\mathbf{4 7}$ & Late & Whenever Bill teaches the course, & it's boring \\
\hline $\mathbf{4 8}$ & Early & Whenever a customer tips, the waiter & is pleased \\
\hline $\mathbf{4 8}$ & Late & Whenever a customer tips the waiter, & he's pleased \\
\hline $\mathbf{4 9}$ & Early & Whenever Rachel leads, the discussion & is exciting \\
\hline $\mathbf{4 9}$ & Late & Whenever Rachel leads the discussion, & it's exciting \\
\hline $\mathbf{5 0}$ & Early & Whenever Mary writes, the paper & is excellent \\
\hline $\mathbf{5 0}$ & Late & Whenever Mary writes the paper, & it's excellent \\
\hline
\end{tabular}

(and the location of its phrase boundary, indicated grammatically and orthographically with a comma) and responded by pressing " 1 " or " 2 " on the keyboard to indicate if they thought the first version or second version was spoken in a way that better matched the on-screen version of the sentence. The grammatical difference between the two spoken utterances on each trial was cued by pitch differences (Pitch), duration differences (Duration), or both pitch and duration differences (Combined). Subjects completed three blocks of 42 trials. Stimuli were counterbalanced, with half of the presentations indicating early closure and half late closure. Each participant judged each stimulus in every condition, across the 3 lists. The task was performed online using Gorilla Experiment Builder and lasted approximately 25 minutes.

\section{Statistical analysis}

All statistical analyses were performed with $\mathrm{R}$ ( $\mathrm{R}$ Core Team, 2021). Mixed effects models were performed with the lme 4 function.

An earlier version of this article can be found on bioRxiv (DOI: https://doi.org/10.1101/555102).

\section{Results}

\section{Overall performance}

Figure 2 and Figure 3 display all participants' performance in the phrase perception and focus perception tests, respectively. Overall, there was a wide range in performance, with no evidence of ceiling or floor effects. Results from each participant are given as Underlying data (Jasmin, 2021).

\section{Subtest reliability}

Cronbach's alpha was used to calculate reliability for each of the six subtests by first (for each condition and test) creating a matrix with a row for each subject, a column for each item, and the performance score ( 1 vs 0 ) as the value, and then submitting this matrix to the alpha function in R's psych package (Revelle, 2016). For the focus tests, reliability was 0.92 for the Pitch condition, 0.83 for the Duration condition, and 0.92 for the Combined condition. For the phrase test, reliability was 0.73 for the Pitch condition, 0.81 for the Duration condition, and 0.87 for the Combined condition. To summarize, reliability tended to be highest for the Combined condition, and reliability was somewhat higher for the focus tests than for the phrase tests. Overall, however, these reliability scores compare favorably with those of other batteries of prosody perception (Kalathottukaren et al., 2015).

\section{Comparison between conditions}

To examine the relative usefulness of pitch and duration cues in the perception of phrase boundaries and linguistic focus we used mixed effects logistic regression with test (phrase versus focus) and condition (Combined, Pitch, and Duration) as fixed factors, and item and participant as random intercepts. Main effects of condition and task were tested by comparing the full model (Condition + Test + Condition $*$ Test) with a null model that omitted the factor of interest and the interaction term. There was no statistically significant main effect of test ( $p$ $=.06)$. However, there was a main effect of condition $\left(\chi^{2}(4)\right.$ $=126.12, \mathrm{p}<0.001)$ and an interaction between test and condition $\left(\chi^{2}(2)=6.92, \mathrm{p}=0.03\right)$.

FDR-corrected post-hoc paired t-tests revealed that for focus perception, participants performed better on the Combined condition compared to the Duration condition $(\mathrm{OR}=1.47$, $\mathrm{Z}=6.17, \mathrm{p}<.001)$ and also compared to the Pitch condition $(\mathrm{OR}=1.34, \mathrm{Z}=4.63, \mathrm{p}<.001)$. Performance on the Pitch and Duration conditions did not differ $(\mathrm{OR}=1.1, \mathrm{Z}=1.56, \mathrm{p}=.36)$. Similarly, for phrase perception, participants performed better on the Combined condition compared to the Pitch 


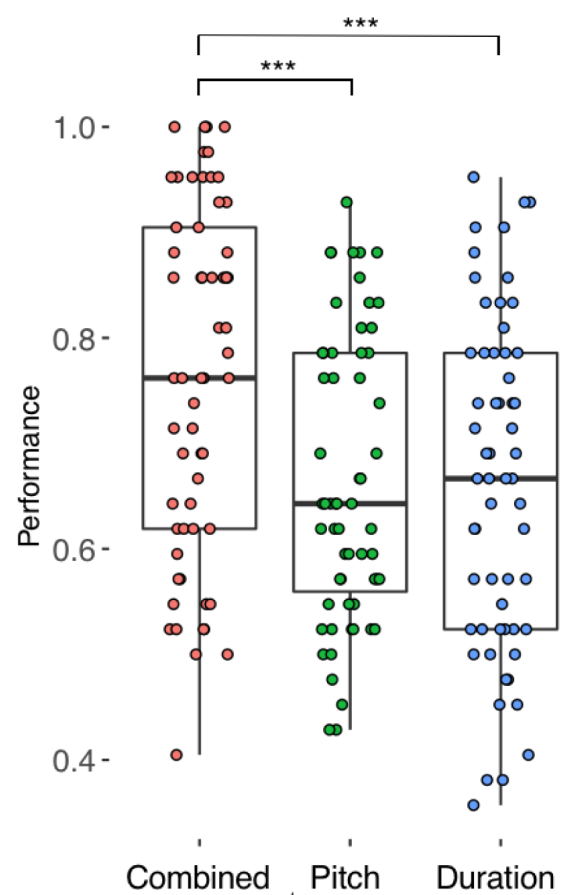

Figure 2. Performance across all 59 participants in each condition of the Phrase Perception test. Horizontal lines indicate median performance.

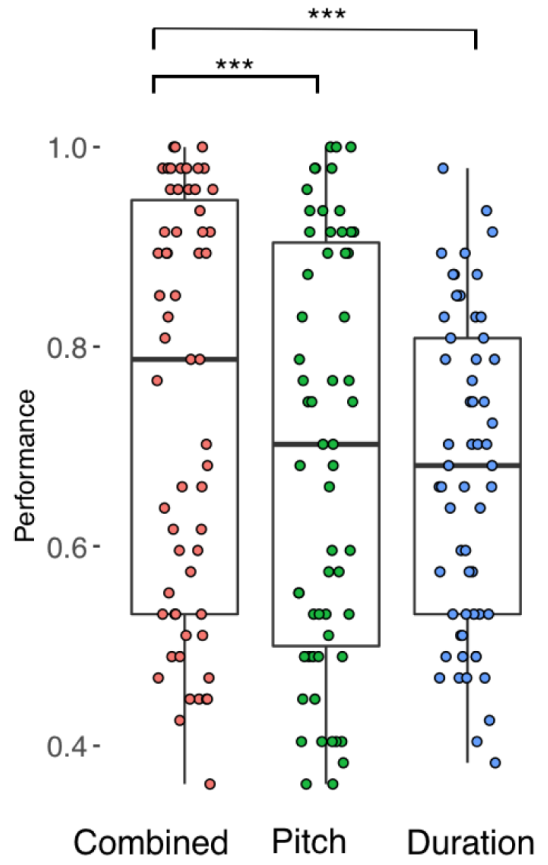

Figure 3. Performance across all 59 participants in each condition of the Focus Perception test. Horizontal lines indicate median performance.
$(\mathrm{OR}=1.70, \mathrm{Z}=7.96, \mathrm{p}<.001)$ and Duration $(\mathrm{OR}=1.71$, $\mathrm{Z}=8.02, \mathrm{p}<.001)$ conditions. Performance on the Duration condition did not differ from the Pitch condition $(\mathrm{OR}=1.00$, $\mathrm{Z}=0.06, \mathrm{p}=1$ ). These results suggest that, across both focus and phrase perception, the presence of an additional cue was generally useful to listeners. Finally, comparisons within each condition, between the two tests was compared. Performance did not differ between the Phrase and Focus tests for the Combined condition ( $\mathrm{OR}=0.9, \mathrm{Z}=-1.22, \mathrm{p}=0.22$ ) or Duration condition $(\mathrm{OR}=1.05, \mathrm{Z}=0.71, \mathrm{p}=.48)$, but performance was marginally (though not significantly) higher in the Pitch condition on the Focus test $(\mathrm{OR}=1.16, \mathrm{Z}=1.92$, $\mathrm{p}=.055)$.

\section{Relationships between conditions}

Pearson's correlations were used to examine the relationship between performance (proportion correct response for each subject) across all six subtests. Correlations are shown along with relationships between all six variables displayed in scatterplots, in Figure 4. Correlations between all conditions were significant, but varied in strength. Generally, correlations between subtests within each prosody test were stronger than correlations between prosody tests. For example, the correlation between performance in the Pitch condition and Duration condition of the focus perception test was $r=0.78$, while the correlation between performance in the Pitch condition of the phrase test and the Duration condition of the focus perception test was $r=0.48$.

The correlation data do not indicate that subtests requiring analysis of similar perceptual cues correlate more strongly. For example, the correlation between the two Duration conditions is not stronger than the correlation between the Duration condition of the focus test and the Pitch condition of the phrase test. This result raises the question of whether the Pitch and Duration conditions are, indeed, indexing different aspects of prosody perception. We investigated this question by conducting two mixed effects multiple logistic regressions, one for Focus and another for Phrase, with performance on the Combined condition (Correct vs Incorrect) as the dependent variable, and performance on the Pitch and Duration conditions (Correct vs Incorrect) as fixed effects, and Item as random effect. For focus perception, we found that Pitch performance $(\mathrm{OR}=3.79, \mathrm{Z}=14.0, \mathrm{p}<0.001)$ and Duration performance $(\mathrm{OR}=2.01, \mathrm{Z}=7.33, \mathrm{p}<0.001)$ explained independent variance in performance in the Combined cues condition. This suggests that perception of focus draws on both pitch and duration perception, but that pitch is relatively more important. For phrase perception, we also found that Pitch performance $(\mathrm{OR}=1.91, \mathrm{Z}=6.57, \mathrm{p}<0.001)$ and Duration performance $(\mathrm{OR}=1.62, \mathrm{Z}=4.91, \mathrm{p}<0.001)$ explained independent variance in performance in the Combined cues condition. This suggests that perception of phrase boundaries draws on both pitch and duration perception, and that both cues are relatively equally important. 


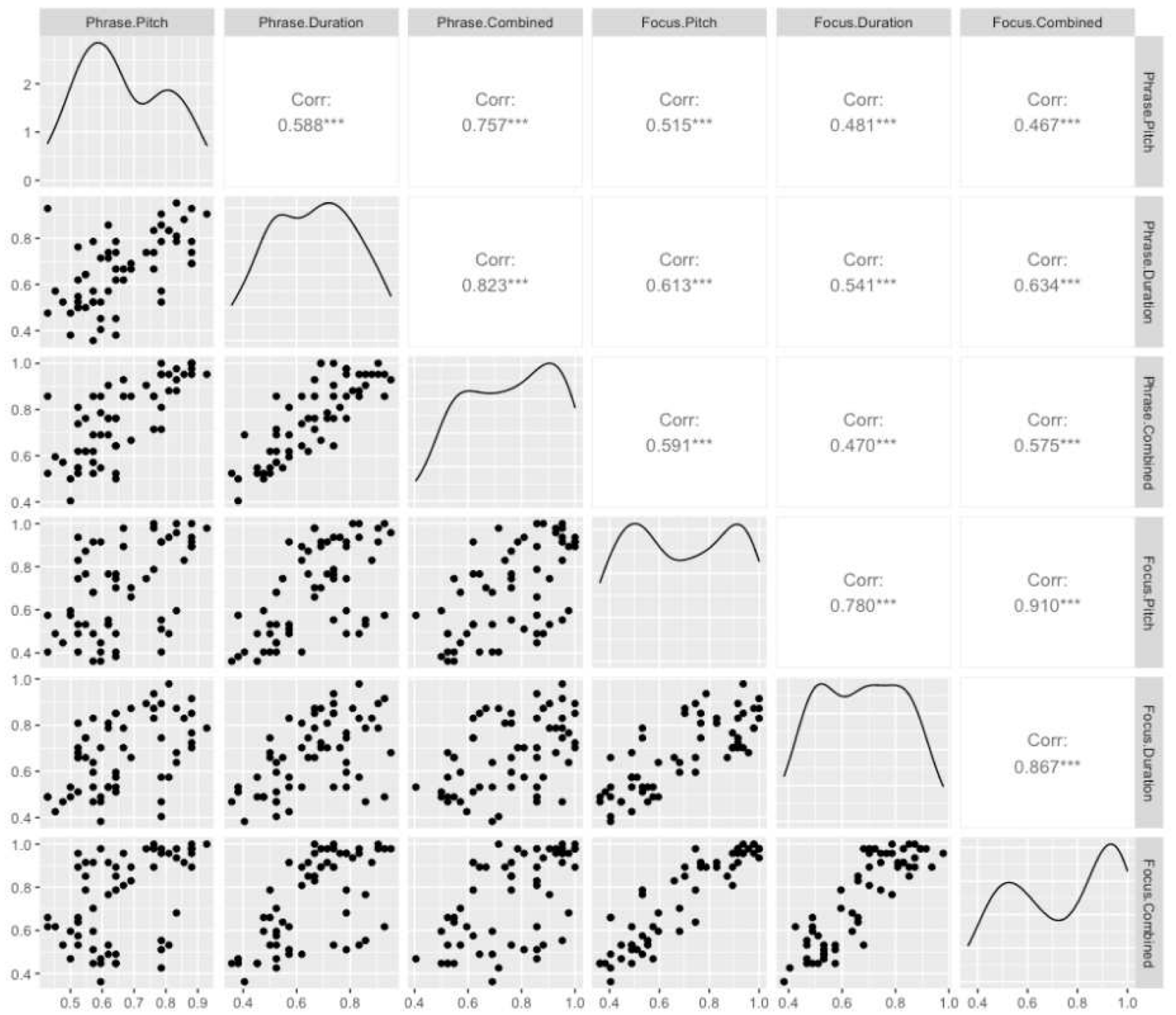

Figure 4. Scatterplots displaying the relationship between performance across each possible pair of all six conditions. The upper triangle shows Pearson correlation coefficients. *** indicates $p<.001$. The diagonal shows variable distributions.

\section{Discussion}

Here we have presented a new battery of prosody perception which is suitable for examining prosody perception in adults. This instrument could facilitate investigation of a number of research questions, such as whether difficulties with prosody perception in individuals with dyslexia or ASD extend into adulthood. Another avenue of investigation would be dialectal variation (see Fuchs, 2016), e.g. whether speakers of other varieties of English are able to use pitch and duration similarly. Second language learning may also be a fruitful line of research using the battery. Indeed, we have recently shown that L2 English speakers of L1 Mandarin tend to perceptually weight pitch highly in perception of English speech (Jasmin et al., 2021). This battery could also be used to test the hypothesis that musical training can enhance focus and phrase boundary perception. This possibility is supported by findings that musical training is linked to enhanced encoding of the pitch of speech (Bidelman et al., 2011; Marques et al., 2007; Moreno \& Besson, 2005; Musacchia et al., 2007; Wong et al., 2007) and syllable durations (Chobert et al., 2011) and that musicians are better than non-musicians at detecting stress contrasts (Kolinsky et al., 2009) and discriminating statements from questions based on intonational contours (Zioga et al., 2016). 


\section{Adaptive difficulty}

The test stimuli for the MBOPP were created using speech morphing software. As a result, the test difficulty is fully customizable (because researchers can select the stimuli with desired cue magnitude) without compromising ecological validity and natural characteristics of the stimuli. The data reported here were collected by setting prosodic cue size to medium levels. This resulted in data that largely avoided both floor and ceiling effects in typically developing adults, although there was some evidence of ceiling performance in the Pitch and Combined cues conditions of the focus perception test. This suggests that to equate difficulty across the focus and phrase perception tests the cue size for the focus perception test should be slightly lower than that for the phrase perception test.

Given that cue size was set here at $50 \%$ of maximum, there remains quite a bit of scope for lowering the difficulty of the test to make it appropriate for other populations who may have lower prosody perception skills, such as children or adults with perceptual difficulties. The ability to modify cue size on a fine-grained level also enables researchers to modify test difficulty on an item-by-item basis. This could have two important uses. First, adaptive prosody perception tests could allow researchers to rapidly find participants' thresholds for accurate prosody perception by modifying test difficulty in response to participants' performance, enabling the use of shorter test protocols. And second, adaptive prosody perception training paradigms could be created by ensuring that participants are presented with stimuli at a difficulty level that is neither so easy as to be trivial nor so difficult as to be frustrating.

\section{Independent modification of individual cues}

Another novel feature of the MBOPP is the ability to modify the size of pitch and duration cues independently. This makes possible investigations into whether prosody perception deficits are dimension-specific in certain populations. For example, we have demonstrated using the MBOPP that adults with amusia demonstrate impaired focus perception in the Pitch condition but perform similarly to typically developing adults on the Duration condition (Jasmin et al., 2020). Investigating the dimension specificity of prosody perception deficits is one way to test the hypothesis that difficulties with prosody perception in a given population stem from auditory deficits. For example, some individuals with ASD have difficulty perceiving prosodic cues to phrase boundaries (Diehl et al., 2008) and linguistic focus (Peppé et al., 2011). ASD has also been linked to impaired duration discrimination (Brenner et al., 2015; Karaminis et al., 2016; Martin et al., 2010) but preserved pitch discrimination and memory for pitch sequences (Heaton et al., 2008; Jarvinen-Pasley et al., 2008b; Stanutz et al., 2014). If prosodic deficits in ASD stem from abnormalities in auditory processing, then they should reflect the unique auditory processing profile of individuals with ASD, and prosodic impairments should be greater for perception and production of duration-based prosodic cues compared to pitch-based prosodic cues. On the other hand, if impairments are present across all conditions, regardless of the acoustic cue presented, this would suggest that prosodic difficulties in ASD stem primarily from modality-general deficits in the understanding of emotional and pragmatic aspects of language.

\section{The role of pitch and durational cues in focus and phrase perception}

Speech tends to be structurally degenerate, i.e. a given speech category is often conveyed by multiple acoustic cues simultaneously. This property may make speech robust to both external background noise (Winter, 2014) and internal "noise" related to imprecise representation of auditory information (Patel, 2014). In support of this idea, we found that performance on the Combined cues condition surpassed that of either single-cue condition for both phrase perception and focus perception, in alignment with previous findings that rising pitch and increased duration are more effective cues to phrase boundaries when presented simultaneously (Cumming, 2010).

\section{Limitations}

The MBOPP currently has several limitations which should be kept in mind by users but could be addressed in future versions of the battery. First, all test items were spoken by a single talker. As a result, the relative usefulness of pitch versus duration cues for a given prosodic feature may reflect that talker's idiosyncratic patterns of cue use rather than, more generally, the usefulness of those cues across talkers. Second, only English test items are included, specifically, from a speaker of Standard Southern British English. It seems uncontroversial to say that, although spoken by a minority, this accent is widely understood across the English-speaking world, so we expect a high level of familiarity with this accent from TV, films, newscasts and teaching materials, at least. However, it is possible that British residents may have some advantage on this test due to greater familiarity with this accent. We consider the use of SSBE here a starting point, and a worthwhile goal for future research would be to develop additional versions of the battery targeted at speakers of other varieties of English. A third limitation is that, currently, only two aspects of prosody perception are included, focus perception and phrase boundary detection. Stress perception and emotion perception are two particularly important aspects of prosody perception which will be included in future versions.

\section{Data availability}

\section{Underlying data}

Multidimensional Battery of Prosody Perception. OSF: http://doi. org/10.17605/OSF.IO/EAQBJ (Jasmin, 2021)

MBOPP_Data.csv contains deidentified results for each battery item for each participant. 
Anastasiou D, Protopapas A: Difficulties in lexical stress versus difficulties in segmental phonology among adolescents with dyslexia. Sci Stud Read. 2015; 19(1): 31-50.

Publisher Full Text

Anwyl-Irvine AL, Massonnié J, Flitton A, et al.: Gorilla in our Midst: An online behavioral experiment builder. Behav Res Methods. 2019; 52(1): 388-407.

PubMed Abstract | Publisher Full Text | Free Full Text

Beach CM: The interpretation of prosodic patterns at points of syntactic structure ambiguity: evidence for cue trading relations. J Mem Lang. 1991; 30(6): 644-663.

Publisher Full Text

Bidelman GM, Gandour JT, Krishnan A: Cross-domain effects of music and language experience on the representation of pitch in the human auditory brainstem. J Cogn Neurosci. 2011; 23(2): 425-434.

PubMed Abstract | Publisher Full Text

Breen M, Fedorenko E, Wagner M, et al.: Acoustic correlates of information structure. Language and cognitive processes. 2010; 25(7-9): 1044-1098. Publisher Full Text

Breen M, Kaswer L, Van Dyke JA, et al.: Imitated Prosodic Fluency Predicts Reading Comprehension Ability in Good and Poor High School Readers. Front Psychol. 2016; 7: 1026.

PubMed Abstract | Publisher Full Text | Free Full Text

Brenner LA, Shih VH, Colich NL, et al.: Time reproduction performance is associated with age and working memory in high-functioning youth with autism spectrum disorder. Autism Res. 2015; 8(1): 29-37.

PubMed Abstract | Publisher Full Text | Free Full Tex

Calet N, Gutierrez-Palma N, Simpson IC, et al.: Suprasegmental phonology development and reading acquisition: a longitudinal study. Sci Stud Read. 2015; 19(1): 51-71.

Publisher Full Text

Chevallier C, Noveck I, Happé F, et al.: From acoustics to grammar: perceiving and interpreting grammatical prosody in adolescents with Asperger Syndrome. Res Autism Spectr Disord. 2009; 3(2): 502-516.

Publisher Full Text

Chobert J, Marie C, François C, et al.: Enhanced passive and active processing of syllables in musician children. J Cogn Neurosci. 2011; 23(12): 3874-3887. PubMed Abstract | Publisher Full Text

Choi JY, Hasegawa-Johnson M, Cole J: Finding intonational boundaries using acoustic cues related to the voice source. J Acoust Soc Am. 2005; 118(4): 2579-2587.

PubMed Abstract | Publisher Full Text

Chrabaszcz A, Winn M, Lin CY, et al.: Acoustic cues to perception of word stress by English, Mandarin, and Russian speakers. J Speech Lang Hear Res. 2014: 57(4): 1468-1479.

PubMed Abstract | Publisher Full Text | Free Full Text

Clin E, Wade-Woolley L, Heggie L: Prosodic sensitivity and morphological awareness in children's reading. Jxp Child Psychol. 2009; 104(2): 197-213. PubMed Abstract | Publisher Full Text

Cumming RE: The interdependence of tonal and durational cues in the perception of rhythmic groups. Phonetica. 2010; 67(4): 219-242.

PubMed Abstract | Publisher Full Text

Cumming R, Wilson A, Leong V, et al.: Awareness of Rhythm Patterns in Speech and Music in Children with Specific Language Impairments. Front Hum Neurosci. 2015; 9: 672.

PubMed Abstract | Publisher Full Text | Free Full Text

de Pijper JR, Sanderman AA: On the perceptual strength of prosodic boundaries and its relation to suprasegmental cues. J Acoust Soc Am. 1994; 96(4): 2037-2047.

Publisher Full Text

Defior S, Gutiérrez-Palma N, Cano-Marín MJ: Prosodic awareness skills and literacy acquisition in Spanish. J Psycholinguis Res. 2012; 41(4): 285-294. PubMed Abstract | Publisher Full Text

Diehl JJ, Bennetto L, Watson D, et al.: Resolving ambiguity: a psycholinguistic approach to understanding prosody processing in high-functioning autism. Brain Lang. 2008; 106(2): 144-152.

PubMed Abstract | Publisher Full Text | Free Full Text

Diehl J, Friedberg C, Paul R, et al.: The use of prosody during syntactic processing in children and adolescents with autism spectrum disorders. Dev Psychopathol. 2015; 27(3): 867-884.

PubMed Abstract | Publisher Full Text

Fisher J, Plante E, Vance $R$, et al.: Do children and adults with language impairment recognize prosodic cues? J Speech Lang Hear Res. 2007; 50(3): 746-758.

PubMed Abstract | Publisher Full Text

Fodor J: Learning to parse? J Psycholinguist Res. 1998; 27: 285-319.

Publisher Full Text

Frazier L, Carlson K, Clifton C Jr: Prosodic phrasing is central to language

comprehension. Trends Cogn Sci. 2006; 10(6): 244-249.

PubMed Abstract | Publisher Full Text
Fry DB: Experiments in the perception of stress. Lang Speech. 1958: 1(2): 126-152.

Publisher Full Text

Fuchs R: Speech Rhythm in Varieties of English. Evidence from Educated Indian English and British English. Singapore: Springer, 2016.

Publisher Full Text

Globerson E, Amir N, Kishon-Rabin L, et al.: Prosody recognition in adults with high-functioning autism spectrum disorders: from psychoacoustics to cognition. Autism Res. 2015; 8(2): 153-163.

PubMed Abstract | Publisher Full Text

Golan O, Baron-Cohen S, Hill JJ, et al.: The 'Reading the Mind in the Voice' test-revised: a study of complex emotion recognition in adults with and without autism spectrum conditions. J Autism Dev Disord. 2007; 37(6): 1096-1106.

PubMed Abstract | Publisher Full Text

Goswami U, Gerson D, Astruc L: Amplitude envelope perception, phonology and prosodic sensitivity in children with developmental dyslexia. Read Writ. 2010; 23(8): 995-1019.

Publisher Full Text

Goswami U, Mead N, Fosker T, et al.: Impaired perception of syllable stress in children with dyslexia: a longitudinal study. J Mem Lang. 2013; 69(1): 1-17. Publisher Full Text

Groen $\mathrm{M}$, Veenendaal N, Verhoeven L: The role of prosody in reading comprehension: evidence from poor comprehenders.J Res Read. 2019; 42(1): 37-57.

Publisher Full Text

Haake C, Kob M, Willmes K, et al.: Word stress processing in specific language impairment: auditory or representational deficits? Clin Linguist Phon. 2013; 27(8): 594-615.

PubMed Abstract | Publisher Full Text

Heaton P, Hudry K, Ludlow A, et al:: Superior discrimination of speech pitch and its relationship to verbal ability in autism spectrum disorders. Cogn Neuropsychol. 2008; 25(6): 771-782.

PubMed Abstract | Publisher Full Text

Holliman A, Williams G, Mundy I, et al.: Beginning to disentangle the prosodyliteracy relationship: a multi-component measure of prosodic sensitivity. Reading and Writing. 2014; 27: 255-266.

Publisher Full Text

Holliman A, Wood C, Sheehy K: The contribution of sensitivity to speech rhythm and non-speech rhythm to early reading development. Educ Psychol. 2010a; 30(3): 247-267.

Publisher Full Text

Holliman A, Wood C, Sheehy K: Does speech rhythm sensitivity predict children's reading ability 1 year later? J Educ Psychol. 2010b; 102(2): 356-366. Publisher Full Text

Holliman AJ, Wood C, Sheehy K: A cross-sectional study of prosodic sensitivity and reading difficulties. J Res Read. 2012; 35(1): 32-48. Publisher Full Text

Holt LL, Lotto AJ: Speech perception as categorization. Atten Percep Psychophys. 2010; 72(5): 1218-1227.

PubMed Abstract | Publisher Full Text | Free Full Text

Hyde KL, Peretz I: Brains that are out of tune but in time. Psychol Sci. 2004; 15(5): 356-360.

PubMed Abstract | Publisher Full Text

Järvinen-Pasley A, Peppé S, King-Smith G, et al.: The relationship between form and function level receptive prosodic abilities in autism. J Autism Dev Disord. 2008a; 38(7): 1328-1340.

PubMed Abstract | Publisher Full Text

Järvinen-Pasley A, Wallace GL, Ramus F, et al:: Enhanced perceptual

processing of speech in autism. Dev Sci. 2008b; 11(1): 109-121.

PubMed Abstract | Publisher Full Text

Jasmin K: MBOPP. 2021

http://www.doi.org/10.17605/OSF.IO/EAQBJ

Jasmin K, Dick F, Holt LL, et al.: Tailored perception: Individuals' speech and music perception strategies fit their perceptual abilities. J Exp Psychol Gen. 2020; 149(5): 914-934.

PubMed Abstract | Publisher Full Text | Free Full Text

Jasmin K, Sun H, Tierney AT: Effects of language experience on domaingeneral perceptual strategies. Cognition. 2021; 206: 104481.

PubMed Abstract | Publisher Full Text

Jiménez-Fernández G, Gutiérrez-Palma N, Defior S: Impaired stress awareness in Spanish children with developmental dyslexia. Res Dev Disabil. 2015; 37: 152-161.

PubMed Abstract | Publisher Full Text

Kalathottukaren RT, Purdy R, McCormick SC, et al.: Behavioral measures to evaluate prosodic skills: A review of assessment tools for children and adults. Contemp Issues Commun Sci Disord. 2015; 42: 138-154. Publisher Full Text

Karaminis T, Cicchini GM, Neil L, et al.: Central tendency effects in time 
interval reproduction in autism. Sci Rep. 2016; 6: 28570. PubMed Abstract | Publisher Full Text | Free Full Text

Kargas N, López B, Morris P, et al.: Relations Among Detection of Syllable Stress, Speech Abnormalities, and Communicative Ability in Adults With Autism Spectrum Disorders. J Speech Lang Hear Res. 2016; 59(2): 206-215. PubMed Abstract | Publisher Full Text

Kawahara $\mathrm{H}$, Irino $\mathrm{T}$ : Underlying principles of a high-quality speech manipulation system STRAIGHT and its application to speech segregation. In: Speech separation by humans and machines. Springer, Boston, MA. 2005; 167-180.

Publisher Full Text

Kentner G: Linguistic rhythm guides parsing decisions in written sentence comprehension. Cognition. 2012; 123(1): 1-20.

PubMed Abstract | Publisher Full Text

Kidd GR, Watson CS, Gygi B: Individual differences in auditory abilities.

J Acoust Soc Am. 2007; 122(1): 418-435.

PubMed Abstract | Publisher Full Text

Killion MC, Niquette PA, Gudmundsen GI, et al: Development of a quick speech-in-noise test for measuring signal-to-noise ratio loss in normalhearing and hearing-impaired listeners. J Acoust Soc Am. 2004; 116(4 Pt 1): 2395-2405.

PubMed Abstract | Publisher Full Text

Kjelgaard MM, Speer SR: Prosodic facilitation and interference in the resolution of temporary syntactic closure ambiguity. J Mem Lang. 1999; 40(2): 153-194.

Publisher Full Text

Kleinman J, Marciano PL, Ault RL: Advanced theory of mind in highfunctioning adults with autism. J Autism Dev Disord. 2001; 31(1): 29-36. PubMed Abstract | Publisher Full Text

Kolinsky R, Cuvelier $\mathrm{H}$, Goetry V, et al.: Music training facilitates lexical stress processing. Music Perception. 2009; 26(3): 235-246.

Publisher Full Text

Langus A, Marchetto $\mathrm{E}$, Bion $\mathrm{R}$, et al:: Can prosody be used to discover hierarchical structure in continuous speech? J Mem Lang. 2012; 66(1): 285-306

Publisher Full Text

Lehiste I, Olive J, Streeter L: Role of duration in disambiguating syntactically ambiguous sentences. J Acoust Soc Am. 1976; 60: 1199-1202.

Publisher Full Text

Lochrin M, Arciuli J, Sharma M: Assessing the relationship between prosody and reading outcomes in children using the PEPS-C. Sci Stud Read. 2015; 19(1): 72-85.

Publisher Full Text

Lyons M, Schoen Simmons E, Paul R: Prosodic development in middle childhood and adolescence in high-functioning autism. Autism Res. 2014 7(2): 181-196.

PubMed Abstract | Publisher Full Text

Marques C, Moreno S, Castro SL: Musicians detect pitch violation in a foreign language better than nonmusicians: behavioral and electrophysiological evidence. J Cogn Neurosci. 2007; 19(9): 1453-1463.

PubMed Abstract | Publisher Full Text

Marshall CR, Harcourt-Brown S, Ramus F, et al.: The link between prosody and language skills in children with specific language impairment (SLI) and/or dyslexia. Int J Lang Commun Disord. 2009; 44(4): 466-488.

PubMed Abstract | Publisher Full Text

Marslen-Wilson W, Tyler $L$, Warren $P$, et al.: Prosodic effects in minimal attachment. Q J Exp Psychol A. 1992; 45A: 73-87.

Publisher Full Text

Martin JS, Poirier M, Bowler DM: Brief report: Impaired temporal

reproduction performance in adults with autism spectrum disorder.

J Autism Dev Disord. 2010; 40(5): 640-646.

PubMed Abstract | Publisher Full Text

Mattys SL: The perception of primary and secondary stress in English.

Percept Psychophys. 2000: 62(2): 253-265.

PubMed Abstract | Publisher Full Text

Moreno S, Besson M: Influence of musical training on pitch processing: event-related brain potential studies of adults and children. Ann N Y Acad Sci. 2005; 1060(1): 93-97.

PubMed Abstract | Publisher Full Text

Mundy I, Carroll J: Speech prosody and developmental dyslexia: reduced phonological awareness in the context of intact phonological representations. J Cogn Psychol. 2012; 24(5): 560-581.

Publisher Full Text

Musacchia G, Sams M, Skoe E, et al.: Musicians have enhanced subcortical auditory and audiovisual processing of speech and music. Proc Natl Acad SCi US A. 2007; 104(40): 15894-15898.

PubMed Abstract | Publisher Full Text | Free Full Text

Nakatani LH, Schaffer JA: Hearing "words" without words: prosodic cues for word perception. J Acoust Soc Am. 1978; 63(1): 234-245.

PubMed Abstract | Publisher Full Text

Nilsson M, Soli SD, Sullivan JA: Development of the Hearing in Noise Test fo the measurement of speech reception thresholds in quiet and in noise.
J Acoust Soc Am. 1994; 95(2): 1085-1099.

PubMed Abstract | Publisher Full Text

Patel AD: Can nonlinguistic musical training change the way the brain processes speech? The expanded OPERA hypothesis. Hear Res. 2014; 308 98-108.

PubMed Abstract | Publisher Full Text

Paul R, Augustyn A, Klin A, et al.: Perception and production of prosody by speakers with autism spectrum disorders. J Autism Dev Disord. 2005; 35(2): 205-220.

PubMed Abstract | Publisher Full Text

Paul R, Bianchi N, Augustyn A, et al.: Production of Syllable Stress in Speakers with Autism Spectrum Disorders. Res Autism Spectr Disord. 2008; 2(1):

110-124.

PubMed Abstract | Publisher Full Text | Free Full Text

Peppé S, Maxim J, Wells B: Prosodic variation in southern British English. Lang Speech. 2000; 43(Pt 3): 309-334.

PubMed Abstract | Publisher Full Text

Peppé S, McCann J: Assessing intonation and prosody in children with atypical language development: the PEPS-C test and the revised version. Clin Linguist Phon. 2003; 17(4-5): 345-354.

PubMed Abstract | Publisher Full Text

Peppé S, Cleland J, Gibbon F, et al.: Expressive prosody in children with autism spectrum conditions. J Neurolinguistics. 2011; 24(1): 41-53.

Publisher Full Text

Philip RC, Whalley HC, Stanfield AC, et al.: Deficits in facial, body movement and vocal emotional processing in autism spectrum disorders. Psychol Med. 2010; 40(11): 1919-1929.

PubMed Abstract | Publisher Full Text

R Core Team: R: A language and environment for statistical computing. $R$ Foundation for Statistical Computing, Vienna, Austria. 2021.

Reference Source

Revelle W: psych: Procedures for Personality and Psychological Research. Northwestern University, Evanston, Illinois, USA Version = 1.6.4. 2016 Reference Source

Richards S, Goswami U: Auditory Processing in Specific Language Impairment (SLI): Relations With the Perception of Lexical and Phrasal Stress. J Speech Lang Hear Res. 2015; 58(4): 1292-1305.

PubMed Abstract | Publisher Full Text

Rutherford MD, Baron-Cohen S, Wheelwright S: Reading the mind in the voice: a study with normal adults and adults with Asperger syndrome and high functioning autism. J Autism Dev Disord. 2002; 32(3): 189-194. PubMed Abstract | Publisher Full Text

Stanutz S, Wapnick J, Burack JA: Pitch discrimination and melodic memory in children with autism spectrum disorders. Autism. 2014 : 18(2): 137-147. PubMed Abstract | Publisher Full Text

Streeter LA: Acoustic determinants of phrase boundary perception. J Acoust Soc Am. 1978; 64(6): 1582-1592.

PubMed Abstract | Publisher Full Text

Veenendaal N, Groen M, Verhoeven L: The role of speech prosody and text reading prosody in children's reading comprehension. BrJ Educ Psychol. 2014; 84(4): 521-536.

PubMed Abstract | Publisher Full Text

Wade-Woolley L: Prosodic and phonemic awareness in children's reading of long and short words. Read Writ. 2016; 29(3): 371-382.

Publisher Full Text

Wade-Woolley L, Heggie L: The contributions of prosodic and phonological awareness to reading: a review. In J. Thomson \& L. Jarmulowicz, Linguistic Rhythm and Literacy. John Benjamins Publishing Company. 2015; 3-24. Publisher Full Text

Wells B, Peppé S: Intonation abilities of children with speech and language impairments. J Speech Lang Hear Res. 2003; 46(1): 5-20.

PubMed Abstract | Publisher Full Text

Whalley $\mathrm{K}$, Hansen J: The role of prosodic sensitivity in children's reading development. J Res Read. 2006: 29(3): 288-303.

Publisher Full Text

Wilson RH: Development of a speech-in-multitalker-babble paradigm to assess word-recognition performance. J Am Acad Audiol. 2003; 14(9): 453-470. PubMed Abstract

Winter B: Spoken language achieves robustness and evolvability by exploiting degeneracy and neutrality. Bioessays. 2014; 36(10): 960-967. PubMed Abstract | Publisher Full Text

Wong PC, Skoe E, Russo NM, et al.: Musical experience shapes human brainstem encoding of linguistic pitch patterns. Nat Neurosci. 2007; 10(4): 420-422.

PubMed Abstract | Publisher Full Text | Free Full Text

Wood C, Terrell C: Poor readers' ability to detect speech rhythm and perceive rapid speech. BrJ Dev Psychol. 1998; 16(3): 397-413.

Publisher Full Text

Zioga I, Di Bernardi Luft C, Bhattacharya J: Musical training shapes neural responses to melodic and prosodic expectation. Brain Res. 2016: 1650 267-282.

PubMed Abstract | Publisher Full Text | Free Full Text 


\section{Open Peer Review}

\section{Current Peer Review Status:}

\section{Version 2}

Reviewer Report 25 February 2022

https://doi.org/10.21956/wellcomeopenres.19044.r46279

(c) 2022 Groen M. This is an open access peer review report distributed under the terms of the Creative Commons Attribution License, which permits unrestricted use, distribution, and reproduction in any medium, provided the original work is properly cited.

\section{Margriet A. Groen}

Department of Psychology, Lancaster University, Lancaster, UK

My sincere apologies for the delay in reading the revised manuscript. I have now had a chance to do so and in this thorough and thoughtful revision, the authors address all the suggestions and concerns I articulated in my original review. I have no further comments to make and am happy to approve it for indexing.

Competing Interests: No competing interests were disclosed.

Reviewer Expertise: Associations between phonological processing (incl. segmental/phonemic and suprasegmental/prosodic processing) and reading development. Assessment of segmental and suprasegmental aspects of speech. Language and literacy development more broadly.

I confirm that I have read this submission and believe that I have an appropriate level of expertise to confirm that it is of an acceptable scientific standard.

Reviewer Report 25 October 2021

https://doi.org/10.21956/wellcomeopenres.19044.r46280

(C) 2021 Fuchs R. This is an open access peer review report distributed under the terms of the Creative Commons Attribution License, which permits unrestricted use, distribution, and reproduction in any medium, provided the original work is properly cited.

\section{Robert Fuchs}

University of Hamburg, Hamburg, Germany

I'm happy to approve this. I have no further comments. 
Competing Interests: No competing interests were disclosed.

Reviewer Expertise: Acoustic phonetics, sociolinguistics, varieties of English, Second Language Acquisition

I confirm that I have read this submission and believe that I have an appropriate level of expertise to confirm that it is of an acceptable scientific standard.

\section{Version 1}

Reviewer Report 23 March 2020

https://doi.org/10.21956/wellcomeopenres.17096.r37918

(C) 2020 Fuchs $\mathbf{R}$. This is an open access peer review report distributed under the terms of the Creative Commons Attribution License, which permits unrestricted use, distribution, and reproduction in any medium, provided the original work is properly cited.

\section{Robert Fuchs}

University of Hamburg, Hamburg, Germany

The Multidimensional Battery of Prosody Perception presented in this paper will be extremely useful for researchers in a number of areas. In fact, I might very well use it my own research. I thus wholeheartedly endorse its indexing, provided that a few points mentioned below are addressed. In addition to a few minor comments, more substantial comments relate to the statistical analysis of the data (mixed effect regression modelling should be used in order to control for non-independence of individual trials) and the experimental data being published on the online annex (it appears that average across trials are available, but not data for each trial).

Data files: The authors should publish the raw data of experiments coming from the experiments so that other researchers can directly conduct statistical tests comparing their results with yours. The file MBOPP-data.csv does not seem to include this data (Even if it did include data from the experimental results, it would seem to include one data point per condition and participant. This does not appear to be the entire dataset, but averaged results.) In principle, the authors should strive to make as much data available as the protection of the anonymity of the participants allows. This includes information on the outcome of every single trial in the experiment, which stimulus was tested (cf. numbers in the tables containing the stimuli), age, gender and other information on the participants. Without this information, other researchers will not be able to conduct statistical comparisons of their data with your data, making the present data much less useful than it could be.

Dialectal variation: Is the Battery equally suitable for speakers of Southern Standard British English, Manchester English, Scottish English, American English etc.? What is the native accent of the actor who recorded the stimuli? Might participants' familiarity with the native accent of the actor influence performance on the test? 
p.3, "speech perception is thought to be categorizing" -> reference required

p.3, "acoustic patterns on slower time scales" -> "acoustic patterns on longer time scales"

p.3, "Not only has dyslexia has been linked" -> "Not only has dyslexia been linked"

p.4, "However, because these tests do use actual language, they arguably measure auditory discrimination rather than prosody perception per se." -> I don't find this conclusion convincing: Naturalistic stimuli may indeed provide insight into the processing of prosody, if the task is carefully designed.

p.4, "The most widely used battery of prosody perception available for purchase" -> This implies there are others as well. They should be discussed here, at least briefly.

p.5, "morphed together to create intermediate versions" -> I have no personal experience with STRAIGHT, but from my experience with other software I understand that creating truly intermediate versions is not possible. What is possible is, given two recordings $A$ and $B$, to take one of them (say A) and resynthesise it with any durational pattern or any pitch contour, including ones that are intermediate between the durational patterns and pitch contours of $A$ and $B$.

However, the resynthesised version will retain all other voice characteristics of $A$ and thus not be a truly intermediate version of $A$ and $B$.

p.7, "The task could be made more difficult" -> "The task could be made yet more difficult"

p.11, Figure 3 -> Indicate significant differences with asterisks and braces (in this figure and others of the same type)

p.11, "Cronbach's alpha was used to calculate reliability" -> Briefly define how reliability is calculated here

p.12, "Relationship between conditions" -> What is being compared to what here? For focus-focus or phrase-phrase conditions, I assume it is the same trial (i.e. participants and stimulus identical). But what about focus-phrase correlations? Since the sentences vary, there would seem to be a large number of possible conditions to match in the correlations.

p.13, "by conducting two multiple linear regressions" -> Mixed effects regression models with participant and sentence as random factors would be more appropriate here. Linear regression ignores the non-independence of multiple datapoints here and will lead to an increased risk of spurious results.

p.13, "as the dependent variable. For focus perception,... in the both cues of condition" -> Beta (ß) is not a good measure of explained variance, as the authors seem to imply. Instead, use measures such as(Pseudo) R2, ROC etc.

p.13, "This instrument could facilitate investigation of a number of research questions" -> Dialectal variation is another field of application, for example, see the psycholinguistic/sociolinguistic applications in Fuchs, Robert. 2016. Speech Rhythm in Varieties of English. Evidence from Educated Indian English and British English. Singapore: Springer.

p.14, "In support of this idea, we found that performance on the both cues condition surpassed that of either single-cue condition for phase perception" -> But this is the opposite of redundancy. One cue adds information that the other does not provide, hence in the both cues condition performance is better than in either of the single cue conditions. Instead, redundancy comes into play here in that the two cues are not completely orthogonal, i.e. performance in the both cues condition is not simply the sum of performance in the two single cue conditions (discounting ceiling effects).

\section{References}

1. Fuchs R: Speech Rhythm in Varieties of English. 2016. Publisher Full Text 
Is the rationale for developing the new method (or application) clearly explained? Yes

Is the description of the method technically sound?

Yes

Are sufficient details provided to allow replication of the method development and its use by others?

Partly

If any results are presented, are all the source data underlying the results available to ensure full reproducibility?

Partly

Are the conclusions about the method and its performance adequately supported by the findings presented in the article?

Yes

Competing Interests: No competing interests were disclosed.

Reviewer Expertise: Acoustic phonetics, sociolinguistics, varieties of English, Second Language Acquisition

I confirm that I have read this submission and believe that I have an appropriate level of expertise to confirm that it is of an acceptable scientific standard, however I have significant reservations, as outlined above.

Author Response 17 Sep 2021

Kykle Jasmin, Birkbeck University of London, London, UK

Robert Fuchs:

The Multidimensional Battery of Prosody Perception presented in this paper will be extremely useful for researchers in a number of areas. In fact, I might very well use it my own research. I thus wholeheartedly endorse its indexing, provided that a few points mentioned below are addressed. In addition to a few minor comments, more substantial comments relate to the statistical analysis of the data (mixed effect regression modelling should be used in order to control for non-independence of individual trials) and the experimental data being published on the online annex (it appears that average across trials are available, but not data for each trial).

Thanks for the kind words about the study - we're glad you like it. Apologies for the long delay in revision. We agree with your assessment of the statistics, and so we have re-run the tests online such that each participant judged each item in each condition, and re-done the stats using mixed effects models for most cases (excepting the scatterplots of performance correlations between different conditions). 
Data files: The authors should publish the raw data of experiments coming from the experiments so that other researchers can directly conduct statistical tests comparing their results with yours. The file MBOPP-data.csv does not seem to include this data (Even if it did include data from the experimental results, it would seem to include one data point per condition and participant. This does not appear to be the entire dataset, but averaged results.) In principle, the authors should strive to make as much data available as the protection of the anonymity of the participants allows. This includes information on the outcome of every single trial in the experiment, which stimulus was tested (cf. numbers in the tables containing the stimuli), age, gender and other information on the participants. Without this information, other researchers will not be able to conduct statistical comparisons of their data with your data, making the present data much less useful than it could be.

We agree, and the new data reflects this change.

Dialectal variation: Is the Battery equally suitable for speakers of Southern Standard British English, Manchester English, Scottish English, American English etc.? What is the native accent of the actor who recorded the stimuli? Might participants' familiarity with the native accent of the actor influence performance on the test?

This is an interesting question. The speaker was from Reading, England, and his accent is probably best described as Standard Southern British English. It seems uncontroversial to say that, although spoken by a minority, this accent is widely understood across the English-speaking world, so we expect a high level of familiarity with this accent from TV, films, newscasts and teaching materials, at least. It's possible that British residents may have some advantage on this test due to greater familiarity with this accent, but it would be difficult to avoid some limitations along these lines due to the great variety in English accents present worldwide. A worthwhile goal for future research would be to develop additional versions of the battery targeted at speakers of other varieties of English.

We now include the following text in the Discussion section on Limitations: "It seems uncontroversial to say that, although spoken by a minority, this accent is widely understood across the English-speaking world, so we expect a high level of familiarity with this accent from TV, films, newscasts and teaching materials, at least. However, it is possible that British residents may have some advantage on this test due to greater familiarity with this accent. We consider the use of SSBE here a starting point, and a worthwhile goal for future research would be to develop additional versions of the battery targeted at speakers of other varieties of English."

p.3, "speech perception is thought to be categorizing" -> reference required

We now cite:

Holt, L. L., \& Lotto, A. J. (2010). Speech perception as categorization. Attention, 
Perception, \& Psychophysics, 72(5), 1218-1227.

p.3, "acoustic patterns on slower time scales" -> "acoustic patterns on longer time scales"

Corrected.

p.3, "Not only has dyslexia has been linked" -> "Not only has dyslexia been linked"

\section{Corrected.}

p.4, "However, because these tests do use actual language, they arguably measure auditory discrimination rather than prosody perception per se." -> I don't find this conclusion convincing: Naturalistic stimuli may indeed provide insight into the processing of prosody, if the task is carefully designed.

Apologies - there was a missing "not" in that sentence. The mentioned tests do *not* use actual language.

p.4, "The most widely used battery of prosody perception available for purchase" -> This implies there are others as well. They should be discussed here, at least briefly.

Apologies if this is unclear. We do refer to a few other tests in the following paragraph:

“Moreover, there are a number of examples of ceiling effects in the literature on prosody perception in adolescents and adults in research using other prosody perception tests (Chevallier et al., 2008; Lyons et al., 2014; Paul et al., 2005), suggesting that existing methodologies for testing prosody perception are insufficiently challenging for adult participants. Research on prosody would be facilitated by a publicly available test with adaptive difficulty suitable for a range of ages and backgrounds."

p.5, "morphed together to create intermediate versions" -> I have no personal experience with STRAIGHT, but from my experience with other software I understand that creating truly intermediate versions is not possible. What is possible is, given two recordings $A$ and $B$, to take one of them (say A) and resynthesise it with any durational pattern or any pitch contour, including ones that are intermediate between the durational patterns and pitch contours of $A$ and $B$. However, the resynthesised version will retain all other voice characteristics of $A$ and thus not be a truly intermediate version of $A$ and $B$.

Thanks for this. STRAIGHT functions differently from more traditional resynthesis in that both $A$ and $B$ are first decomposed into their power spectrum, fundamental frequency, and an aperiodic component. The power spectrum and aperiodic 
component are the basis for resynthesizing the other voice characteristics (frequency of sibilants, distribution of formants), all of which are set by default to be intermediate between the two recordings. Because these characteristics are estimated by STRAIGHT for both recordings, it is possible to synthesize 'naturalistic' intermediate morphs not just between different tokens from the same talker, but between different talkers with widely varying speech.

To clarify this, we have added this to the last paragraph of the Introduction:

"Speech morphing software (STRAIGHT, Kawahara \& Irino, 2005) was then used to decompose these two recordings, align them onto one another, and resynthesize ("morph") them such that the extent to which pitch and durational patterns cued one prosodic interpretation or the other could be varied independently while all other acoustic characteristics are set to be intermediate between the two recordings."

p.7, "The task could be made more difficult" -> "The task could be made yet more difficult"

\section{Corrected.}

p.11, Figure 3 -> Indicate significant differences with asterisks and braces (in this figure and others of the same type)

We have made this change.

p.11, "Cronbach's alpha was used to calculate reliability" -> Briefly define how reliability is calculated here

We now describe how alpha was calculated:

"Cronbach's alpha was used to calculate reliability for each of the six subtests by first (for each condition and test) creating a matrix with a row for each subject, a column for each item, and the performance score ( 1 vs 0 ) as the value, and then submitting this matrix to the alpha function in R's psych package (Revelle, 2016)."

p.12, "Relationship between conditions" -> What is being compared to what here? For focusfocus or phrase-phrase conditions, I assume it is the same trial (i.e. participants and stimulus identical). But what about focus-phrase correlations? Since the sentences vary, there would seem to be a large number of possible conditions to match in the correlations.

Here we briefly depart from the use of mixed effects models to simply report the proportion correct (performance) on each subject, correlated with performance on each other sub-test. We have amended the text to make this clearer:

"Pearson's correlations were used to examine the relationship between performance (proportion correct response for each subject) across all six subtests." 
p.13, "by conducting two multiple linear regressions" -> Mixed effects regression models with participant and sentence as random factors would be more appropriate here. Linear regression ignores the non-independence of multiple datapoints here and will lead to an increased risk of spurious results.

We now report this using linear mixed effects models.

p.13, "as the dependent variable. For focus perception,... in the both cues of condition" -> Beta (ß) is not a good measure of explained variance, as the authors seem to imply. Instead, use measures such as(Pseudo) R2, ROC etc.

As an effect size measure, we now report odds ratios and $Z$ scores for the terms in the mixed effects logistic regressions.

p.13, "This instrument could facilitate investigation of a number of research questions" -> Dialectal variation is another field of application, for example, see the psycholinguistic/sociolinguistic applications in Fuchs, Robert. 2016. Speech Rhythm in Varieties of English. Evidence from Educated Indian English and British English. Singapore: Springer.

We now mention this research avenue in the first paragraph of the discussion

“Another avenue of investigation would be dialectal variation (see Fuchs, 2016), e.g. whether speakers of other varieties of English are able to use pitch and duration similarly. Second language learning may also be a fruitful line of research using the battery. Indeed, we have recently shown that L2 English speakers of L1 Mandarin tend to perceptually weight pitch highly in perception of English speech (Jasmin et al., 2021)."

p.14, "In support of this idea, we found that performance on the both cues condition surpassed that of either single-cue condition for phase perception" -> But this is the opposite of redundancy. One cue adds information that the other does not provide, hence in the both cues condition performance is better than in either of the single cue conditions. Instead, redundancy comes into play here in that the two cues are not completely orthogonal, i.e. performance in the both cues condition is not simply the sum of performance in the two single cue conditions (discounting ceiling effects).

Thank you for the thoughtful critique. We believe a change in terminology is necessary here - namely that multiple cues indexing the same feature to ensure robustness is referred to as 'degeneracy' in biology and more recently in language science (Winter, 2014). We have amended the paragraph as follows:

"Speech tends to be structurally degenerate, i.e. a given speech category is often conveyed by multiple acoustic cues simultaneously. This property may make speech robust to both external background noise (Winter, 2014) and internal "noise" related to imprecise representation of auditory information ( Patel, 2014). In support of this 
idea, we found that performance on the Combined cues condition surpassed that of either single-cue condition for both phrase perception and focus perception, in alignment with previous findings that rising pitch and increased duration are more effective cues to phrase boundaries when presented simultaneously ( Cumming, 2010 )."

Competing Interests: No competing interests were disclosed.

Reviewer Report 03 March 2020

https://doi.org/10.21956/wellcomeopenres.17096.r37746

(c) 2020 Groen M. This is an open access peer review report distributed under the terms of the Creative Commons Attribution License, which permits unrestricted use, distribution, and reproduction in any medium, provided the original work is properly cited.

\section{Margriet A. Groen}

Department of Psychology, Lancaster University, Lancaster, UK

Dear Dr. Jasmin and colleagues,

I've enjoyed reading this well-written manuscript, describing what I believe to be an innovative and relevant new measure of two aspects of prosody perception (focus perception and phrase boundary perception).

You clearly describe the rationale for its development and set-up. I find the use of morphing software to create the stimuli particularly relevant as it allows tighter experimental control over: 1) the degree to which particular cues are present in the stimulus; and 2) over item difficulty.

I do have some suggestions that I believe would improve the manuscript.

In the introduction, under 'Prosody and reading acquisition', you discuss work linking perception of prosody to word reading, but you don't mention work on the relationship between prosodic processing and reading comprehension. There is a substantial literature on this and some of it you refer to in the manuscript (e.g., Whalley \& Hansen, 2006; Lochrin et al., 2015) but only in the context of word reading. It would be relevant to point to the relation to reading comprehension as well. Holliman et al. (2014) ${ }^{1}$ is another relevant paper. Additionally, some of my own work suggests that children with poor reading comprehension have deficits in prosodic processing, and in particular in speech rhythm perception. You might also want to refer to the 'implicit prosody hypothesis' (Fodor, 1998) ${ }^{2}$ in this context. Also relevant is Kentner (2012) ${ }^{3}$.

In the methods section, you refer to the three conditions as 'Pitch-Only', 'Time-Only' and 'Combined'. In the results section (and the figures), however, you refer to 'pitch', 'time' and 'both'. It would be helpful to be consistent throughout the manuscript in the labelling of the conditions.

In the results section, you report two multiple linear regressions to address the question of 
whether pitch and time account for unique variance in prosody perception. You use the 'TimeOnly' and 'Pitch-Only' conditions as predictors of performance in the 'Combined' condition. I'm not a statistician, but I feel this does not take into account the dependencies in the data, i.e., that the stimulus materials are highly similar across conditions. Responses to the 'Time-Only' version of a sentence are therefore likely to be related to (i.e., NOT independent from) responses to the 'PitchOnly' version of the same sentence. This increases the chance of Type-I errors. The considerable correlations (between .6 and .9) you report indicate this as well. In my view, it would be more appropriate to fit mixed-effects models to the data in which you specify a random effect structure that accounts for the item-dependencies (as well as the participant-dependencies). Lazic (2010) ${ }^{4}$ and Winter $(2011)^{5}$ explain the problem of dependencies in more detail. Winter's new book 'Statistics for Linguists: An Introduction using R' provides a highly intuitive introduction to this problem and its solution (mixed effects models). As yours is primarily a methods paper, I have not listed this as a major revision. I nevertheless feel it would be important to do, or at least provide item-level data (i.e., all responses to all items for all participants), which would allow others to do it.

In the data-file, there are three columns that do not seem to be mentioned in the manuscript (prosody_both, prosody_pitch, prosody_time). It would be helpful to clarify what they refer to.

\section{References}

1. Holliman A, Williams G, Mundy I, Wood C, et al.: Beginning to disentangle the prosody-literacy relationship: a multi-component measure of prosodic sensitivity. Reading and Writing. 2014; 27 (2): 255-266 Publisher Full Text

2. Fodor Jjournal of Psycholinguistic Research. 1998; 27 (2): 285-319 Publisher Full Text

3. Kentner G: Linguistic rhythm guides parsing decisions in written sentence comprehension. Cognition. 2012; 123 (1): 1-20 PubMed Abstract | Publisher Full Text

4. Lazic SE: The problem of pseudoreplication in neuroscientific studies: is it affecting your analysis?. BMC Neurosci. 2010; 11: 5 PubMed Abstract | Publisher Full Text

5. Winter B: Pseudoreplication in Phonetic Research. ICPhS XVII. 2011.

6. Groen $\mathrm{M}$, Veenendaal N, Verhoeven L: The role of prosody in reading comprehension: evidence from poor comprehenders. Journal of Research in Reading. 2019; 42 (1): 37-57 Publisher Full Text

Is the rationale for developing the new method (or application) clearly explained? Yes

Is the description of the method technically sound?

Yes

Are sufficient details provided to allow replication of the method development and its use by others?

Yes

If any results are presented, are all the source data underlying the results available to ensure full reproducibility?

Yes

Are the conclusions about the method and its performance adequately supported by the 


\section{findings presented in the article? \\ Yes}

Competing Interests: No competing interests were disclosed.

Reviewer Expertise: Associations between phonological processing (incl. segmental/phonemic and suprasegmental/prosodic processing) and reading development. Assessment of segmental and suprasegmental aspects of speech. Language and literacy development more broadly.

I confirm that I have read this submission and believe that I have an appropriate level of expertise to confirm that it is of an acceptable scientific standard, however I have significant reservations, as outlined above.

Author Response 17 Sep 2021

Kykle Jasmin, Birkbeck University of London, London, UK

\section{Margariet Groen:}

Dear Dr. Jasmin and colleagues,

I've enjoyed reading this well-written manuscript, describing what I believe to be an innovative and relevant new measure of two aspects of prosody perception (focus perception and phrase boundary perception).

Thank you for these kind words. We're glad you liked the paper. Apologies for the long turnaround on this revision. We needed to collect new data to address your suggestions.

You clearly describe the rationale for its development and set-up. I find the use of morphing software to create the stimuli particularly relevant as it allows tighter experimental control over: 1) the degree to which particular cues are present in the stimulus; and 2) over item difficulty.

I do have some suggestions that I believe would improve the manuscript.

In the introduction, under 'Prosody and reading acquisition', you discuss work linking perception of prosody to word reading, but you don't mention work on the relationship between prosodic processing and reading comprehension. There is a substantial literature on this and some of it you refer to in the manuscript (e.g., Whalley \& Hansen, 2006; Lochrin et al., 2015) but only in the context of word reading. It would be relevant to point to the relation to reading comprehension as well. Holliman et al. $(2014)^{1}$ is another relevant paper. Additionally, some of my own work suggests that children with poor reading comprehension have deficits in prosodic processing, and in particular in speech rhythm perception. You might also want to refer to the 'implicit prosody hypothesis' (Fodor, 1998) ${ }^{2}$ in this context. Also relevant is Kentner $(2012)^{3}$. 
Thank you for the suggestion. We have expanded the introduction so that it now includes a review of research linking prosodic processing to reading comprehension, including the references you suggest here:

"The link between prosody and reading is not limited to word reading, as prosody perception and production have also been shown to be related to reading comprehension (Holliman et al., 2014). Prosody predicts reading comprehension even when a variety of additional linguistic variables are accounted for, including phonological skills and vocabulary (Whalley \& Hansen, 2006; Holliman et al., 2010b; Lochrin et al., 2015; Breen et al., 2016), syntactic awareness (Veenendaal et al., 2014), and decoding (Groen et al., 2019). This link between prosodic skills and reading comprehension could reflect links between prosodic and syntactic processing during reading. Fodor (1998), for example, proposed that readers generate prosodic contours during silent reading, and that these prosodic structures can affect syntactic parsing decisions, a hypothesis later supported by eye-tracking data (Kentner, 2012)."

In the methods section, you refer to the three conditions as 'Pitch-Only', 'Time-Only' and 'Combined'. In the results section (and the figures), however, you refer to 'pitch', 'time' and 'both'. It would be helpful to be consistent throughout the manuscript in the labelling of the conditions.

We now consistently use the simpler terms "Pitch", “Duration", and "Combined".

In the results section, you report two multiple linear regressions to address the question of whether pitch and time account for unique variance in prosody perception. You use the 'Time-Only' and 'Pitch-Only' conditions as predictors of performance in the 'Combined' condition. I'm not a statistician, but I feel this does not take into account the dependencies in the data, i.e., that the stimulus materials are highly similar across conditions. Responses to the 'Time-Only' version of a sentence are therefore likely to be related to (i.e., NOT independent from) responses to the 'Pitch-Only' version of the same sentence. This increases the chance of Type-I errors. The considerable correlations (between .6 and .9) you report indicate this as well. In my view, it would be more appropriate to fit mixed-effects models to the data in which you specify a random effect structure that accounts for the item-dependencies (as well as the participant-dependencies). Lazic (2010) ${ }^{4}$ and Winter $(2011)^{5}$ explain the problem of dependencies in more detail. Winter's new book 'Statistics for Linguists: An Introduction using R' provides a highly intuitive introduction to this problem and its solution (mixed effects models). As yours is primarily a methods paper, I have not listed this as a major revision. I nevertheless feel it would be important to do, or at least provide item-level data (i.e., all responses to all items for all participants), which would allow others to do it

Thank you for the suggestion; new data has been collected such that each participant saw each item in each condition, and stats have been re-run using mixed effects models to account for these item-wise dependencies. Throughout the paper we now use mixed effects models, with the exception of when examining correlations between performance across all 6 sub-tests. However, we also now publish the complete trial-wise dataset so readers can reanalyse the data as they prefer and as 


\section{methods develop.}

In the data-file, there are three columns that do not seem to be mentioned in the manuscript (prosody_both, prosody_pitch, prosody_time). It would be helpful to clarify what they refer to.

These columns are not present in the new data file.

Competing Interests: No competing interests were disclosed. 